\author{
FEDERAL RESERVE BANK OF SAN FRANCISCO \\ WORKING PAPER SERIES
}

\title{
Innovative Growth Accounting
}

\author{
Peter J. Klenow \\ Stanford University \\ Huiyu Li \\ Federal Reserve Bank of San Francisco
}

April 2020

Working Paper 2020-16

https://www.frbsf.org/economic-research/publications/working-papers/2020/16/

\section{Suggested citation:}

Klenow, Peter J., Huiyu Li. 2020. “Innovative Growth Accounting,” Federal Reserve Bank of San Francisco Working Paper 2020-16. https://doi.org/10.24148/wp2020-16

The views in this paper are solely the responsibility of the authors and should not be interpreted as reflecting the views of the Federal Reserve Bank of San Francisco or the Board of Governors of the Federal Reserve System. 


\title{
Innovative Growth Accounting
}

\author{
Peter J. Klenow \\ Huiyu $\mathrm{Li}^{*}$ \\ Stanford University \\ Federal Reserve Bank of SF
}

April 10, 2020

\begin{abstract}
Recent work highlights a falling entry rate of new firms and a rising market share of large firms in the United States. To understand how these changing firm demographics have affected growth, we decompose productivity growth into the firms doing the innovating. We trace how much each firm innovates by the rate at which it opens and closes plants, the market share of those plants, and how fast its surviving plants grow. Using data on all nonfarm businesses from 1982-2013, we find that new and young firms (ages 0 to 5 years) account for almost one-half of growth - three times their share of employment. Large established firms contribute only one-tenth of growth despite representing one-fourth of employment. Older firms do explain most of the speedup and slowdown during the middle of our sample. Finally, most growth takes the form of incumbents improving their own products, as opposed to creative destruction or new varieties.
\end{abstract}

*Klenow: Stanford University and NBER; Li: Federal Reserve Bank of San Francisco. We thank Mark Bils, John Haltiwanger, Hugo Hopenhayn, Chang-Tai Hsieh, and Erik Hurst for useful comments. We also thank Amber Flaharty and Gladys Teng for excellent research assistance. Any opinions and conclusions expressed herein are those of the author(s) and do not necessarily represent the views of the U.S. Census Bureau or the Federal Reserve System. This research was performed at a Federal Statistical Research Data Center under FSRDC Project Number 1440. All results have been reviewed to ensure that no confidential information is disclosed. 


\section{Introduction}

Solow (1956) famously decomposed output growth into contributions from capital, labor, and productivity. Mankiw, Romer and Weil (1992) further decomposed productivity into human capital versus residual productivity. We take this residual productivity, routinely calculated by the U.S. Bureau of Labor Statistics, as our starting point. We attribute productivity growth to innovation and ask: what form does the innovation take, and which firms do most of the innovation?

Innovation can take the form of a stream of new varieties that are not close substitutes for any existing varieties (Romer, 1990). Alternatively, growth could be driven by creative destruction of existing products as in Aghion and Howitt (1992). Examples include Walmart stores driving out mom-and-pop stores or Amazon stealing business from physical stores. Yet another possibility is that growth takes the form of existing producers improving their own products (e.g., successive generations of Apple iPhones or new car models). Even conditional on the form of innovation, growth could be led by entrants and young firms (e.g., Uber or Netflix) or by older and larger firms (e.g., Intel or Starbucks).

U.S. productivity growth has been lackluster in recent decades, except for a decade-long surge from the mid-1990s through the mid-2000s. ${ }^{1}$ At the same time, firm entry rates have fallen and reallocation of labor across incumbent firms has slowed - coined "declining business dynamism" by papers such as Decker, Haltiwanger, Jarmin and Miranda (2014). Large, established superstar firms have captured a bigger share of markets. Is this declining dynamism and rising concentration responsible for the growth slowdown? Have superstar firms helped growth or hindered it?

We offer a new growth decomposition to shed light on these questions. We decompose growth into three types of innovation: creative destruction, brand new varieties, and innovation by incumbents on their own products. We further decompose each of these sources into contributions by firm age and size.

\footnotetext{
${ }^{1}$ See Fernald (2015) for discussion on the timing of the productivity speedup and slowdown.
} 
We exploit firm and plant data on employment at all nonfarm businesses from 1983-2013 in the U.S. Census Bureau's Longitudinal Business Database (LBD). We treat each plant as a unique product (or set of products). This enables us to observe the rate and importance of product entry and exit across firms. We rely on a model in which employment at a plant is isoelastic with respect to the quality of products produced at the plant. ${ }^{2}$ We use the size of entering versus exiting plants to gauge the quality of brand new products and the quality improvements made through creative destruction. We assess quality improvements by firms on their own products using changes in employment over time at surviving incumbent plants. We also allow the lowest quality products (plants) to exit due to obsolescence (i.e, inability to keep up with overall quality and variety growth) as in Hopenhayn (1992). ${ }^{3}$

We preview our findings as follows. Some $60 \%$ of growth on average comes from incumbent innovations on their own products, whereas about $27 \%$ comes from new varieties and 13\% from creative destruction. Many exiting plants are quite small, suggesting much of exit is due to obsolescence rather than creative destruction. And new plants are smaller than incumbent plants on average, making us infer that most plant entry takes the form of new varieties rather than creative destruction.

We find that own innovation drove both the mid-1990s speedup and the mid-2000s slowdown of growth. TFP growth averaged $1.15 \%$ per year from $1982-$ 1995, then sped up to $2.82 \%$ per year from 1996-2005 before falling back to 1.03\% per year from 2006-2013. Own innovation accounted for 148 of the 167 basis point acceleration, and 144 of the 179 basis point deceleration. Even though entry and job reallocation fell throughout the sample, growth from creative destruction accelerated modestly from 1996-2005 versus 1982-1995.

\footnotetext{
${ }^{2}$ We model product heterogeneity as coming from quality differences, but these will be isomorphic to differences in process efficiency in our model setting.

${ }^{3}$ We do not model the arrival rates and step sizes of innovation, but rather back them out from data moments in the LBD. We allow them to vary over time and across firms. In this sense, we are not assuming these arrival rates and step sizes are exogenous. Instead, we are estimating and carrying out a model-based growth decomposition.
} 
New firms in a given year account for about $1 / 3$ of growth on average. New and young firms (ages $0-5$ years) together contribute roughly $1 / 2$ of all growth, despite employing less than 1/5 of all workers. Older incumbents (ages 6 and above) contribute the other half of growth. Such established firms played a bigger role in the speedup and slowdown of growth, however, accounting for $80 \%$ of the pickup and $70 \%$ of the dropoff.

The largest firms - those with 5,000 or more workers - accounted for only $11 \%$ of growth on average. This is less than half of their $25 \%$ share of employment. Small firms, with fewer than 20 employees, explain over $60 \%$ of growth despite employing only $21 \%$ of all workers. This is very much in the spirit of Haltiwanger, Jarmin and Miranda (2013), who emphasize the outsized contribution of young, small fast-growing firms ("gazelles") to gross job creation.

The speedup and slowdown of growth occurred uniformly across the size distribution. In particular, firms with (i) less than 20 employees, (ii) between 20 and 249 employees, (iii) between 250 and 4999 employees, and (iv) 5000 or more employees, each produced a speedup and slowdown of around 40 basis points. Thus, in this accounting, superstar firms did not generate the bulk of the boom or bust. Focusing on the role of superstars in creating or hindering growth at least directly - seems misplaced. It is possible, of course, that the rise of superstar firms discouraged innovation by other firms, as in Aghion, Bergeaud, Boppart, Klenow and Li (2020).

The rest of the paper proceeds as follows. Section 2 relates our paper to the existing literature. Section 3 lays out the model we use to do innovation accounting. Section 4 presents the mapping from model parameters to the moments in the LBD. Section 5 provides our main results. Section 6 discusses further results and directions for future research. Section 7 concludes. 


\section{Related Literature}

The classic reference on creative destruction models is Aghion and Howitt (1992). Klette and Kortum (2004) developed potential implications of creative destruction for firm dynamics. Lentz and Mortensen (2008) formally estimated a generalization of the Klette-Kortum model using data on Danish firms. See Aghion, Akcigit and Howitt (2014) for a survey of the literature on both models and evidence of creative destruction. Aghion, Bergeaud, Boppart, Klenow and Li (2019) analyze how creative destruction can be missed in measures of aggregate productivity growth. Hsieh, Klenow and Nath (2019) develop and calibrate a twocountry version of the Klette-Kortum model.

Romer (1990) is the seminal paper on expanding variety models. RiveraBatiz and Romer (1991) followed up with a two-economy version. Acemoglu (2003) and Jones (2016) are two of many subsequent models built around variety growth. Chapter 12 of Acemoglu (2011) provides a textbook treatment. Feenstra (1994) and Broda and Weinstein (2006) estimate variety gains from imports. Broda and Weinstein (2006) estimate growth in the range of consumer products available.

Krusell (1998) was an early paper modeling innovation by incumbent firms on their own products. Lucas and Moll (2014) can be interpreted to be in this vein. See chapter 12 of Aghion and Howitt (2009) and chapter 14 of Acemoglu (2011) for models combining own innovation with creative destruction. Other papers with multiple types of innovation include Luttmer (2011), Akcigit and Kerr (2018), and Peters (2019). Atkeson and Burstein (2019) analyze optimal policy in the presence multiple innovation channels. They emphasize that the social return to creative destruction is smaller than to own innovation or to the creation of new varieties. From a policy perspective, therefore, we care about the importance of each type of innovation in overall growth.

Perhaps the closest paper to ours is Garcia-Macia, Hsieh and Klenow (2019). They too use LBD data to infer the types of innovation behind U.S. growth in 
recent decades. The key distinction is that they look only at firms. By exploiting data on plants and assuming plants proxy for varieties produced by a firm, we are able to directly infer the sources of growth. Garcia-Macia et al. resort to indirect inference, and also make simplifying assumptions such as that the step-size of innovations is the same for own innovation and creative destruction. We are able to relax this assumption, and even allow step sizes for all types of innovation to differ by the size and age of firms.

Our model also features exit of the lowest quality products due to obsolescence. Hopenhayn (1992) is a pioneering model with this feature. Hopenhayn, Neira and Singhania (2018) is a recent application to understand the falling entry rate. Akcigit and Ates (2019) and Peters and Walsh (2019) analyze the causes of both falling entry and falling growth. Other efforts to explain lackluster recent growth include Engbom (2017) and Liu, Mian and Sufi (2019).

Our approach builds on Feenstra (1994), which infers quality and variety growth from a product's market share. Feenstra showed that one can back out underlying quality and variety using a CES demand elasticity and the market share of a product. Hottman, Redding and Weinstein (2016) follow the Feenstra approach, and have the advantage of directly seeing products at a detailed level. They also observe prices and quantities, so they can adjust for markups when inferring a product's quality. Due to data constraints, we abstract from markup dispersion across products. The tradeoff is that we look beyond consumer packaged goods to the entire nonfarm business sector.

With data on prices and quantities and products, one could adjust not only for markups but for other factors driving a wedge between a plant's employment and the quality and variety of its products. This includes adjustment costs, financial frictions, and capital intensity of production. One could focus more narrowly on U.S. manufacturing and control for such factors. Following Foster, Haltiwanger and Syverson (2008), one could separate "TFPQ" from "TFPR" by netting out the influence of markups, adjustment costs, factor intensity and so on - and then apply our direct inference to TFPQ data to determine 
the sources of innovation. See Hsieh and Klenow $(2009,2014)$ and Eslava and Haltiwanger (2019) for efforts along these lines.

Just as growth accounting does not require that capital or labor be determined exogenously, our innovative growth accounting does not require that innovation rates be exogenous. For this reason, our accounting is not inconsistent with the literature arguing that innovation rates are sustained only because of growth in research efforts. See, for example, Jones (1995) and Bloom, Jones, Van Reenen and Webb (2017).

Less consistent with our approach are decompositions of productivity growth into within-firm, reallocation, and entry-exit terms by Baily, Hulten and Campbell (1992), Griliches and Regev (1995), Olley and Pakes (1996), and Melitz and Polanec (2015). A prominent implementation is Foster, Haltiwanger and Krizan (2001), and more recent versions are Decker, Haltiwanger, Jarmin and Miranda (2017) and Gutiérrez and Philippon (2019). Baqaee and Farhi (2020) show that such statistical decompositions are not derived from explicit general equilibrium models. Thus, although these decompositions provide useful moments that models should match, they do not provide a direct way to infer the sources of innovation and growth.

In particular, the above decompositions use growth in firm labor productivity to evaluate innovation within firms. Figures 1 and 2 compare growth in revenue per worker (labor productivity) to growth in employment for Walmart and Amazon based on Compustat data. ${ }^{4}$ For Walmart, employment grew rapidly while labor productivity grew comparatively little. For Amazon, revenue productivity did grow markedly, but employment growth was much faster still. Figures 3 through 7 in the Appendix cover Microsoft, Google, Facebook, Apple and Starbucks. In all of these firms employment growth dwarfed growth in revenue per worker. All of these firms were famously innovative. The consistent byprod-

\footnotetext{
${ }^{4}$ The Census LBD, which we use for almost all of our estimates, does not have data on revenue, and the U.S. Census Bureau forbids us from revealing the identity of firms. Hence we compare measures of revenue labor productivity with employment growth for innovative firms in Compustat.
} 
Figure 1: Walmart

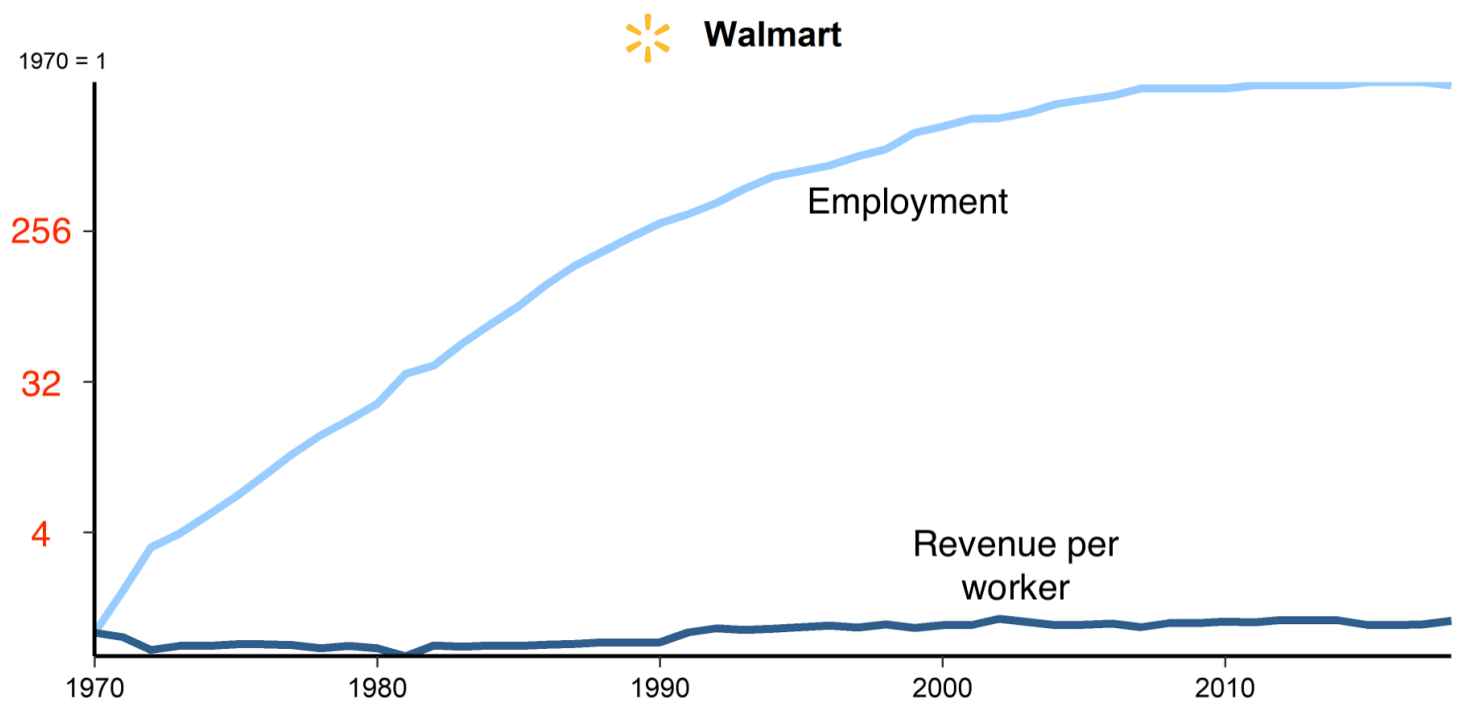

Figure 2: Amazon

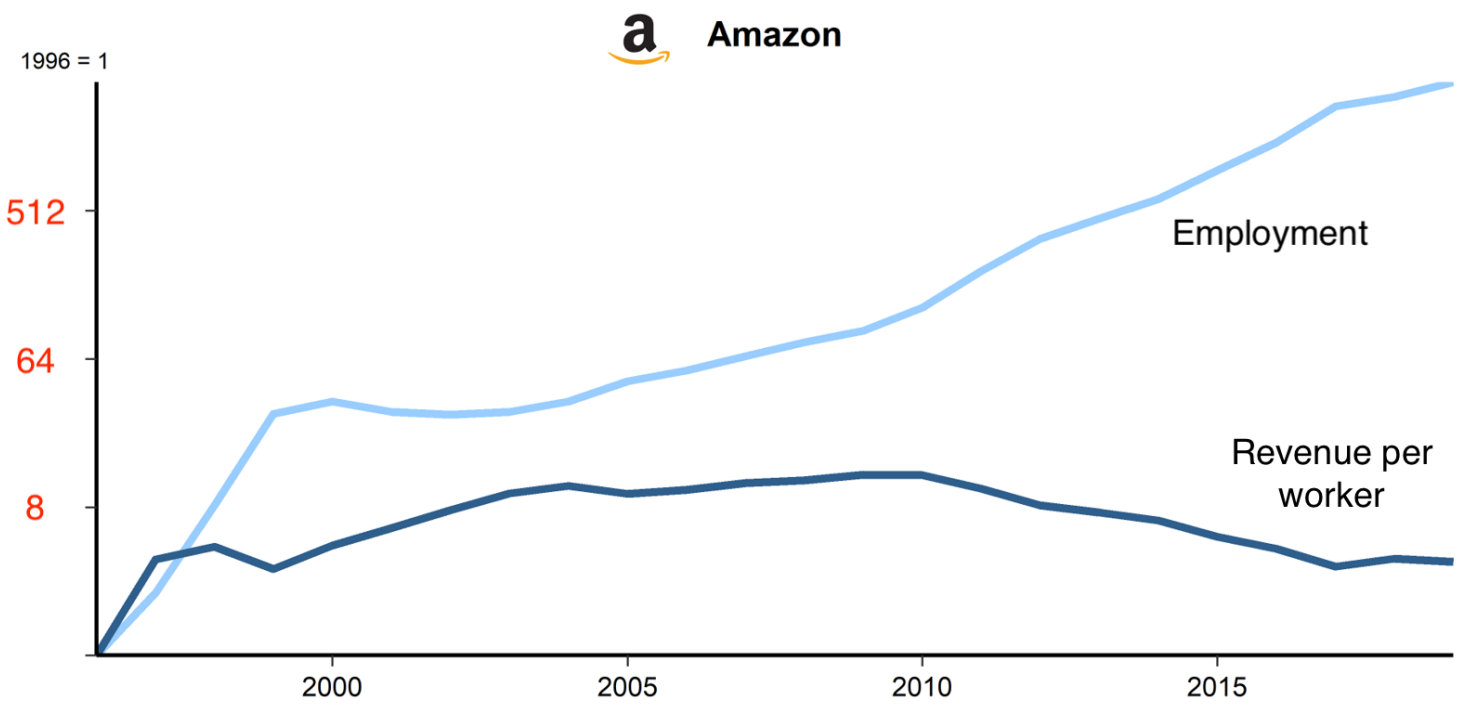

Source: WRDS Compustat and BEA Table 1.1.9. Revenue per worker = "REVT / (GDP Deflator $\mathrm{x}$ EMP)", Employment = "EMP" and Year = "FYEAR". The graph displays revenue per worker and employment relative to the first year when both series are available for the firm. 
uct of their innovation would appear to be swift employment growth rather than revenue productivity growth. This suggests their innovation may have taken the form of adding more markets and products (which would could show up in employment rather than necessarily boosting their price-cost markups and showing up in revenue productivity).

In our framework, revenue productivity is actually the same across plants and firms, as each plant chooses labor input to equate marginal revenue with a common marginal cost of labor. Hence, in our setup, a firm's revenue productivity does not contain any information about a firm's contribution to growth. Instead, a firm's contribution to growth will manifest in its rising market share (which we proxy with employment, as it is easy to observe and measure). From this perspective, the rising market share of Walmart, Amazon, and other superstar firms is consistent with their outsized innovation and contribution to growth.

As stressed by Hsieh and Klenow (2017) and Garcia-Macia et al. (2019), however, not all market share gains are equal when it comes to their contribution to growth. Creative destruction entails more job creation than growth, since only the net improvement beyond existing technology adds to growth. For this reason we are keen to use the entry and exit of plants to disentangle a firm's own innovation and variety creation versus from its creative destruction.

\section{Innovation accounting}

This section lays out a model wherein aggregate productivity growth comes from innovation by firms. The model connects a firm's growth contribution to the market share of its entering, surviving, and exiting products. The market share dynamics of its surviving products shed light, in particular, on the rate at which the firm improves it's own products. 


\subsection{Final goods production}

There is a continuum of intermediate products $i \in\left[0, N_{t}\right]$, with $N_{t}$ denoting the total measure of varieties in period $t . N_{t}$ can change over time due to the introduction of new varieties and the obsolescence of low quality products. Omitting time subscripts, aggregate output $Y$ in a given period is a CES aggregate of intermediate varieties:

$$
Y=\left[\int_{0}^{N}[q(i) y(i)]^{\frac{\sigma-1}{\sigma}} d i\right]^{\frac{\sigma}{\sigma-1}}
$$

where $y(i)$ is the quantity of variety $i$ and $q(i)$ is its quality. Parameter $\sigma>1$ is the elasticity of substitution between varieties.

Profit maximization by competitive final goods producers generates the demand function for variety $i$ :

$$
y(i)=\left(\frac{P(i)}{P}\right)^{-\sigma} q(i)^{\sigma-1} Y
$$

where $P(i)$ is the price of variety $i$ and $P$ is the aggregate price index

$$
P=\left[\int_{0}^{N}[P(i) / q(i)]^{1-\sigma} d i\right]^{\frac{1}{1-\sigma}}
$$

Let $p(i):=\frac{P(i)}{P}$ denote the relative price of good $i$. Demand for a product increases with its quality and decreases with its price.

\subsection{Intermediate goods production}

Each intermediate good $i$ can be produced by a monopolistically competitive producer at a constant marginal cost equal to the competitive wage $W$. The profit-maximizing price given demand (1) is the familiar constant markup over marginal cost:

$$
P(i)=\mu \cdot W,
$$


where $\mu:=\frac{\sigma}{\sigma-1}>1$. The markup is lower when products are closer substitutes. We can also write the relative price as

$$
p(i)=\mu \cdot w
$$

where $w:=W / P$ is the real marginal cost.

Substituting the aggregate price index (2) and the profit-maximizing price into (1) yields the expenditure share (and employment share) of a product:

$$
s(i)=\frac{P(i) y(i)}{P Y}=\frac{l(i)}{L}=\frac{q(i)^{\sigma-1}}{\int_{0}^{N} q(i)^{\sigma-1} d i} .
$$

We can define an aggregate quality index as

$$
Q:=\left(\int_{0}^{N} q(i)^{\sigma-1} d i\right)^{\frac{1}{\sigma-1}} .
$$

Substituting this definition into (3), a product's market share can be written as

$$
s(i)=\left(\frac{q(i)}{Q}\right)^{\sigma-1} .
$$

The market share of a product increases with its relative quality with elasticity $\sigma-1$.

Growth in this model is due to growth in the aggregate quality index $Q$. Using $y(i)=s(i) L$ in the aggregate production function, aggregate output is

$$
Y=\left[\int_{0}^{N}(q(i) s(i))^{\frac{\sigma-1}{\sigma}} d i\right]^{\frac{\sigma}{\sigma-1}} L=Q \cdot L .
$$

We are interested in the growth rate of aggregate productivity $Y / L$ :

$$
g_{t}:=\ln \frac{Y_{t}}{L_{t}}-\ln \frac{Y_{t-1}}{L_{t-1}}=\ln \frac{Q_{t}}{Q_{t-1}}
$$




\subsection{Innovation}

We next describe the innovation process that drives the growth in $Q$. We are interested in attributing growth to groups of firms or individual firms. Let $\mathcal{M}_{t}$ denote the set of all firms in the economy in period $t$. The set of firms can change over time from entry of new firms and exit of firms that lose all of their products. Let $\mathcal{E}_{t}$ and $\mathcal{X}_{t-1}$ denote the set of firms entering and exiting between $t-1$ and $t$. Let $\mathcal{C}_{t, t-1}$ denote the set of continuing firms that operate in both $t$ and $t-1$. By construction, the set of firms in $t$ is the union of new and continuing firms $\mathcal{M}_{t}=\mathcal{E}_{t} \cup \mathcal{C}_{t, t-1}$, and the set of firms in $t-1$ is the union of exiting and continuing firms $\mathcal{M}_{t-1}=\mathcal{X}_{t-1} \cup \mathcal{C}_{t, t-1}$.

We denote the set of products produced by firm $f$ in period $t$ as $\mathcal{N}_{f t}$ set of products. The complete set of products produced in $t$ is therefore $\mathcal{N}_{t}=$ $\left\{\mathcal{N}_{f t}\right\}_{f \in \mathcal{M}_{t}}$. The set of products produced by a firm and the quality of those products can change due to innovation. There are three types of innovation: 1) creative destruction, 2) own-innovation and 3) new varieties. With creative destruction, the producer of an existing product is replaced by a better producer. With own-innovation, a producer innovates on one of its own products. A new variety expands the set of products. We allow the arrival rate and step size of each type of innovation to depend on the innovating firm. In addition, products disappear due to obsolescence when their quality is below a threshold $\kappa_{t}$.

Let $\mathcal{N} \mathcal{V}_{t}, \mathcal{C D}_{t}, \mathcal{O I}_{t}$ and $\mathcal{O}_{t-1}$ denote the set of new varieties, creatively destroyed products, products experiencing own innovation, and those becoming obsolete between $t$ and $t-1$, respectively. Let $\mathcal{S}_{t}$ denote the set of products that are produced in $t$ and $t-1$ with constant quality. The set of products in $t$ is $\mathcal{N}_{t}=\mathcal{N} \mathcal{V}_{t} \cup \mathcal{C} \mathcal{D}_{t} \cup \mathcal{O} \mathcal{I}_{t} \cup \mathcal{S}_{t}$, while the set of products in $t-1$ is $\mathcal{N}_{t-1}=\mathcal{O}_{t-1} \cup \mathcal{C} \mathcal{D}_{t} \cup \mathcal{O I}_{t} \cup \mathcal{S}_{t}$.

The timing of events in a period is as follows: firms hire labor and produce, then obsolete products exit, then new varieties are created and existing products are creatively destroyed, and finally own-innovation occurs on surviving incumbent products. Quality levels after innovation apply to production in the 
next period. Our assumption that obsolete products exit before innovation ensures that firms only carry out innovation on products that are not obsolete.

More precisely, after production products with quality $q_{t-1}<\kappa_{t}$ become obsolete and exit the market. Let $\widetilde{x}_{f, t-1}^{O}$ denote the share of products of firm $f \in \mathcal{M}_{t-1}$ that exit due to obsolescence:

$$
\widetilde{x}_{f, t-1}^{O}=\frac{\int_{i \in \mathcal{N}_{f, t-1}} 1\left\{q_{t-1}(i)<\kappa_{t}\right\} d i}{N_{f, t-1}}=: G_{f, t-1}\left(\kappa_{t}\right)
$$

where $G_{f, t-1}(q)$ is the cumulative distribution of quality for firm $f$ in period $t-1$.

After exit of obsolete products, each surviving firm and new firm $f \in \mathcal{M}_{t}$ brings in $\nu_{f t} N_{t-1}$ new varieties for production in period $t$. The quality of a new variety is drawn from the distribution of non-obsolete varieties in period $t-1$ with a step size $V_{f t}$. These firms may also replace existing producers of $\delta_{f t} N_{t-1}$ non-obsolete products by improving on the quality of those products by step size $\Delta_{f t}$. If the firm $f$ was active in period $t-1$, then it loses some of the products it produced in $t-1$ to creative destruction and obsolescence. For the products it keeps, it randomly innovates on share $\widetilde{o}_{f t}$ with step size $O_{f t}$.

Let $\mathcal{N} \mathcal{V}_{f t}, \mathcal{C} \mathcal{D}_{f t}$ and $\mathcal{O I}_{f t}$ denote the set of products of firm $f$ that are new varieties, acquired through creative destruction, or have enjoyed own-innovation, respectively. Let $\mathcal{X}_{f, t-1}^{C D}$ and $\mathcal{X}_{f, t-1}^{O}$ denote the set of products which firm $f$ loses through creative destruction and obsolescence, respectively. Finally, let $\mathcal{S}_{f t}$ denote the set of products that $f$ produces in both $t$ and $t-1$ with constant quality. The set of products $f$ produces in $t$ is therefore $\mathcal{N}_{f t}=\mathcal{N V}_{f t} \cup \mathcal{C} \mathcal{D}_{f t} \cup \mathcal{O} \mathcal{I}_{f t} \cup \mathcal{S}_{f t}$, while the set it produces in $t-1$ is $\mathcal{N}_{f, t-1}=\mathcal{X}_{f, t-1}^{C D} \cup \mathcal{X}_{f, t-1}^{O} \cup \mathcal{S}_{f t}$. A firm exits the market when it does not have any products.

Thus, the share of products in $t-1$ that is subject to creative destruction is

$$
\delta_{t}:=\int_{f \in \mathcal{M}_{t}} \delta_{f t} d f
$$


Similarly, the rate of arrival of new varieties between $t-1$ and $t$ is

$$
\nu_{t}:=\int_{f \in \mathcal{M}_{t}} \nu_{f t} d f
$$

We need to specify how firms lose their products to creative destruction. Let $\widetilde{x}_{f, t-1}^{C D} N_{f, t-1}$ be the number of products a firm active in $t-1$ loses between $t-1$ and $t$ due to creative destruction. In equilibrium, the arrival rate of creative destruction equals the sum of the rate of product exit due to creative destruction. That is,

$$
\delta_{t}=\int_{f \in \mathcal{M}_{t-1}} \widetilde{x}_{f, t-1}^{C D} \frac{N_{f, t-1}}{N_{t-1}} d f=\int_{f \in \mathcal{M}_{t-1}} x_{f, t-1}^{C D} d f
$$

where $x_{f, t-1}^{C D}:=\widetilde{x}_{f, t-1}^{C D} \frac{N_{f, t-1}}{N_{t-1}}$. For simplicity we assume creative destruction is random so that all firms lose the same fraction of non-obsolete products, denoted by $\widehat{\delta}_{t}$. This implies that, for all firms in $t-1$,

$$
\widetilde{x}_{f, t-1}^{C D}=\widehat{\delta}_{t}\left[1-G_{f, t-1}\left(\kappa_{t}\right)\right] .
$$

Therefore, the share of products of a firm in $t-1$ that are not produced by the firm in $t$ is

$$
\widetilde{x}_{f, t-1}=\widetilde{x}_{f, t-1}^{O}+\widetilde{x}_{f, t-1}^{C D}=G_{f, t-1}\left(\kappa_{t}\right)+\widehat{\delta}_{t}\left[1-G_{f, t-1}\left(\kappa_{t}\right)\right],
$$

and the aggregate exit rate of product from producers at the end of $t-1$ is

$$
x_{t-1}=\int_{f \in \mathcal{M}_{t-1}} \widetilde{x}_{f, t-1} \frac{N_{f, t-1}}{N_{t-1}} d f=\widehat{\delta}_{t}\left[1-G_{t-1}\left(\kappa_{t}\right)\right]+G_{t-1}\left(\kappa_{t}\right) .
$$

The net growth rate in the number of varieties $N_{t}$ is the difference between the rate of new variety arrival and the rate of obsolescence:

$$
N_{t}=\left[1+\nu_{t}-G_{t-1}\left(\kappa_{t}\right)\right] \cdot N_{t-1} .
$$

Recall that $\widetilde{o}_{f t}$ is the fraction of the products that survive both creative de- 
struction and obsolescence which experience own innovation by incumbent firm $f$. I.e., the share of products of firm $f$ that experience own innovation is

$$
\widetilde{o}_{f t} \cdot\left(1-\widetilde{x}_{f, t-1}^{C D}-\widetilde{x}_{f, t-1}^{O}\right)=\widetilde{o}_{f t} \cdot\left(1-\widehat{\delta}_{t}\right) \cdot\left[1-G_{f, t-1}\left(\kappa_{t}\right)\right]
$$

and the share of all products in $t-1$ that experience own innovation is

$$
\left(1-\widehat{\delta}_{t}\right) \int_{f \in \mathcal{M}_{t-1}} \widetilde{o}_{f t}\left[1-G_{f, t-1}\left(\kappa_{t}\right)\right] \frac{N_{f, t-1}}{N_{t-1}} d f
$$

\subsection{Aggregate productivity growth}

Having laid out the innovation process, how does this process translate into aggregate productivity growth? Using $\mathcal{N}_{t}=\mathcal{N} \mathcal{V}_{t} \cup \mathcal{C D}_{t} \cup \mathcal{O} \mathcal{I}_{t} \cup \mathcal{S}_{t}$, we can decompose growth $g_{t}=\ln \frac{Q_{t}}{Q_{t-1}}$ into innovation types:

$$
\begin{aligned}
e^{g} & =\left(\frac{\int_{i \in \mathcal{N}_{t}} q_{t}(i)^{\sigma-1} d i}{\int_{i \in \mathcal{N}_{t-1}} q_{t-1}(i)^{\sigma-1} d i}\right)^{\frac{1}{\sigma-1}} \\
& =\left(\frac{\int_{i \in \mathcal{N}_{t}} q_{t}(i)^{\sigma-1} d i+\int_{i \in \mathcal{C} \mathcal{D}_{t}} q_{t}(i)^{\sigma-1} d i+\int_{i \in \mathcal{O I}_{t}} q_{t}(i)^{\sigma-1} d i+\int_{i \in \mathcal{S}_{t}} q_{t}(i)^{\sigma-1} d i}{\int_{i \in \mathcal{N}_{t-1}} q_{t-1}(i)^{\sigma-1} d i}\right)^{\frac{1}{\sigma-1}}
\end{aligned}
$$

The first term on the right hand side captures new varieties. Since the quality of new varieties is drawn randomly from the distribution of non-obsolete products (plus a firm-specific step size), this term simplifies to

$\frac{\int_{i \in \mathcal{N} \mathcal{V}_{t}} q_{t}(i)^{\sigma-1} d i}{\int_{i \in \mathcal{N}_{t-1}} q_{t-1}(i)^{\sigma-1} d i}=\frac{\int_{f \in \mathcal{M}_{t}} \nu_{f} N_{t-1} \frac{\left(V_{f} \widehat{Q}_{t-1}\right)^{\sigma-1}}{N_{t-1}} d f}{Q_{t-1}^{\sigma-1}}=\left(\int_{f \in \mathcal{M}_{t}} \nu_{f} V_{f}^{\sigma-1} d f\right)\left(\frac{\widehat{Q}}{Q}\right)^{\sigma-1}$

where $\widehat{Q}^{\sigma-1}:=N_{t-1} \mathbb{E}_{G_{t-1}}\left(q^{\sigma-1} \mid q \geq \kappa_{t}\right)$. $\widehat{Q}$ is the aggregate quality of nonobsolete products. Since $\widehat{Q} \geq Q$, a given arrival rate of innovation $\left(\nu_{t}\right)$ generates more growth when the innovation happens on non-obsolete products. Hence, we will refer to

$$
\int_{f \in \mathcal{M}_{t}} \nu_{f} V_{f}^{\sigma-1} d f
$$


as the growth contribution of new varieties and refer to

$$
\left(\int_{f \in \mathcal{M}_{t}} \nu_{f} V_{f}^{\sigma-1} d f\right)\left(\left(\frac{\widehat{Q}}{Q}\right)^{\sigma-1}-1\right)
$$

as the contribution of obsolescence to growth. This Hopenhayn term is the interaction of selection of obsolete products and innovation on the non-obsolete products.

With the assumption that creative destruction is random, we can simplify the second term in (4) to

$$
\frac{\int_{f \in \mathcal{M}_{t}} \Delta_{f}^{\sigma-1} \int_{i \in \mathcal{C} \mathcal{D}_{f t}} q_{t-1}(i)^{\sigma-1} d i d f}{Q_{t-1}^{\sigma-1}}=\left(\int_{f \in \mathcal{M}_{t}} \delta_{f} \Delta_{f}^{\sigma-1} d f\right)\left(\frac{\widehat{Q}}{Q}\right)^{\sigma-1}
$$

The third term in (4) is due to incumbent own innovation. This is a randomly drawn $\widetilde{o}_{f t}$ fraction of incumbent $f$ 's products that survived obsolescence and creative destruction. Therefore, the third term in (4) only applies to continuing firms and is equal to

$$
\begin{aligned}
& \left(1-\widehat{\delta}_{t}\right) \int_{f \in \mathcal{C}_{t, t-1}} \widetilde{o}_{f t} O_{f}^{\sigma-1} \int_{i \in \mathcal{N}_{f t-1}, q_{t-1}(i) \geq \kappa} \frac{q_{t-1}^{\sigma-1}(i)}{Q_{t-1}^{\sigma-1}} d i d f \\
= & \left(1-\widehat{\delta}_{t}\right)\left(\frac{\widehat{Q}}{Q}\right)^{\sigma-1} \int_{f \in \mathcal{C}_{t, t-1}} \widetilde{o}_{f t}\left(1-G_{f, t-1}\left(\kappa_{t}\right)\right) O_{f}^{\sigma-1} \frac{N_{f, t-1} \mathbb{E}_{G_{f, t-1}}\left(q^{\sigma-1} \mid q \geq \kappa_{t}\right)}{\widehat{Q}_{t-1}^{\sigma-1}} d f \\
= & \left(\frac{\widehat{Q}}{Q}\right)^{\sigma-1} \int_{f \in \mathcal{C}_{t, t-1}} o_{f t} O_{f}^{\sigma-1} \frac{\mathbb{E}_{G_{f, t-1}}\left(q^{\sigma-1} \mid q \geq \kappa_{t}\right)}{\mathbb{E}_{G_{t-1}}\left(q^{\sigma-1} \mid q \geq \kappa_{t}\right)} d f
\end{aligned}
$$

where $o_{f t}:=\widetilde{o}_{f t}\left(1-\widehat{\delta}_{t}\right)\left(1-G_{f, t-1}\right) \frac{N_{f, t-1}}{N_{t-1}}$ denotes the arrival rate of own innovation by $f$ relative to the total number of products in $t-1$. 
The fourth term in (4) contains products that survive creative destruction and obsolescence but do not experience own innovation. This term is equal to

$$
\begin{aligned}
& \left(1-\widehat{\delta}_{t}\right) \int_{f \in \mathcal{C}_{t, t-1}}\left(1-\widetilde{o}_{f t}\right) \int_{i \in \mathcal{N}_{f t-1}, q_{t-1}(i) \geq \kappa t} \frac{q_{t-1}^{\sigma-1}(i)}{Q_{t-1}^{\sigma-1}} d i d f \\
= & \left(\frac{\widehat{Q}}{Q}\right)^{\sigma-1}\left(1-\widehat{\delta}_{t}\right) \int_{f \in \mathcal{C}_{t, t-1}}\left(1-\widetilde{o}_{f t}\right) \frac{\left(1-G_{f, t-1}\right) N_{f, t-1}}{N_{t-1}} \frac{\mathbb{E}_{G_{f, t-1}\left(\kappa_{t}\right)}\left(q^{\sigma-1} \mid q \geq \kappa_{t}\right)}{\mathbb{E}_{G_{t-1}}\left(q^{\sigma-1} \mid q \geq \kappa_{t}\right)} d f .
\end{aligned}
$$

The third and fourth terms in (4) combined equal the net change in quality of products that are produced by the same producer in $t$ and $t-1$ :

$$
\begin{aligned}
& \left(\frac{\widehat{Q}}{Q}\right)^{\sigma-1} \int_{f \in \mathcal{C}_{t, t-1}} o_{f t}\left(O_{f}^{\sigma-1}-1\right) \frac{\mathbb{E}_{G_{f, t-1}}\left(q^{\sigma-1} \mid q \geq \kappa_{t}\right)}{\mathbb{E}_{G_{t-1}}\left(q^{\sigma-1} \mid q \geq \kappa_{t}\right)} d f \\
+ & \left(\frac{\widehat{Q}}{Q}\right)^{\sigma-1}\left(1-G_{t-1}\left(\kappa_{t}\right)-\delta_{t}\right)
\end{aligned}
$$

Combining our derivations for the right hand side terms of (4), we can express aggregate growth in terms of arrival rates and step sizes. Using

$$
\delta_{t}=\int_{f \in \mathcal{M}_{t}} \delta_{f t} d f=\widehat{\delta}_{t} \int_{f \in \mathcal{M}_{t-1}}\left[1-G_{f, t-1}\left(\kappa_{t}\right)\right] \frac{N_{f, t-1}}{N_{t-1}} d f
$$

we can write the growth rate as

$$
\begin{aligned}
e^{g(\sigma-1)} & =1+\int_{f \in \mathcal{M}_{t}} \nu_{f} V_{f}^{\sigma-1}+\delta_{f}\left(\Delta_{f}^{\sigma-1}-1\right) d f+\int_{f \in \mathcal{C}_{t, t-1}} o_{f t}\left(O_{f}^{\sigma-1}-1\right) \frac{\mathbb{E}_{G_{f, t-1}}\left(q^{\sigma-1}\right)}{\mathbb{E}_{G_{t-1}}\left(q^{\sigma-1}\right)} d f \\
& +\left(\int_{f \in \mathcal{M}_{t}} \nu_{f} V_{f}^{\sigma-1}+\delta_{f}\left(\Delta_{f}^{\sigma-1}-1\right) d f\right)\left(\left(\frac{\widehat{Q}}{Q}\right)^{\sigma-1}-1\right) \\
& +\int_{f \in \mathcal{C}_{t, t-1}} o_{f t}\left(O_{f}^{\sigma-1}-1\right) \frac{\mathbb{E}_{G_{f, t-1}}\left(q^{\sigma-1} \mid q \geq \kappa_{t}\right)-\mathbb{E}_{G_{f, t-1}}\left(q^{\sigma-1}\right)}{\mathbb{E}_{G_{t-1}}\left(q^{\sigma-1}\right)} d f \\
& -\left(1-\left(\frac{\widehat{Q}}{Q}\right)^{\sigma-1}\left[1-G_{t-1}\left(\kappa_{t}\right)\right]\right)
\end{aligned}
$$

The first line of the right hand side of equation (5) is the sum of the growth con- 
tributions from new varieties, creative destruction, and own innovation. The second and third lines on the right hand side of equation (5) are positive contributions from obsolescence through selection, while the last line is the negative contribution based on the market share in $t-1$ of varieties lost to obsolescence.

\subsection{Firm contribution to growth}

In addition to decomposing growth into types of innovation and obsolescence, we are also interested accounting for the contribution of firms or groups of firms. Define the contribution of firm $f \in \mathcal{M}_{t} \cup \mathcal{X}_{t-1}$ to growth between $t$ and $t-1$ as

$$
\begin{aligned}
g_{f} & :=\nu_{f} V_{f}^{\sigma-1}+\delta_{f}\left(\Delta_{f}^{\sigma-1}-1\right) \\
& +o_{f t} N_{t-1}\left(O_{f}^{\sigma-1}-1\right) \mathbb{E}_{G_{f, t-1}}\left[s_{t-1}\right] \\
& +o_{f t} N_{t-1}\left(O_{f}^{\sigma-1}-1\right)\left(\mathbb{E}_{G_{f, t-1}}\left[s_{t-1} \mid q \geq \kappa_{t}\right]-\mathbb{E}_{G_{f, t-1}}\left[s_{t-1}\right]\right) \\
& +\left(\int_{j \in \mathcal{M}_{t}} \nu_{j} V_{j}^{\sigma-1}+\delta_{j}\left(\Delta_{j}^{\sigma-1}-1\right) d j\right)\left(\left(\frac{\widehat{Q}}{Q}\right)^{\sigma-1}-1\right) \frac{G_{f, t-1}\left(\kappa_{t}\right) N_{f, t-1}}{G_{t-1}\left(\kappa_{t}\right) N_{t-1}} \\
& -\mathbb{E}_{G_{f, t-1}}\left[s_{t-1} \mid q<\kappa_{t}\right] G_{f, t-1}\left(\kappa_{t}\right) N_{f, t-1}
\end{aligned}
$$

where $s_{t-1}$ is the market share of a product in $t-1$. The first two lines on the right hand side of (6) are firm $f$ 's contribution through new varieties, creative destruction and own-innovation. The third line is the positive contribution from own-innovation focusing on non-obsolete products. The fourth line captures the contribution of obsolescence through improving the quality distribution that new varieties and creative destruction build upon. To attribute the aggregate contribution of obsolescence to individual firms, we multiply the fourth line by firm f's share of obsolete products. The final line is firm's $f$ 's negative contribution to growth from losing its obsolete varieties. 
For new firms, $g_{f}$ simplifies to their contributions from new varieties and creative destruction, respectively:

$$
g_{f}=\nu_{f} V_{f}^{\sigma-1}+\delta_{f}\left(\Delta_{f}^{\sigma-1}-1\right) .
$$

Firms that exit, meanwhile, contribute only through obsolescence:

$$
\begin{aligned}
g_{f} & =\left(\int_{j \in \mathcal{M}_{t}} \nu_{j} V_{j}^{\sigma-1}+\delta_{j}\left(\Delta_{j}^{\sigma-1}-1\right) d j\right)\left(\left(\frac{\widehat{Q}}{Q}\right)^{\sigma-1}-1\right) \frac{G_{f, t-1}\left(\kappa_{t}\right) N_{f, t-1}}{G_{t-1}\left(\kappa_{t}\right) N_{t-1}} \\
& -\mathbb{E}_{G_{f, t-1}}\left[s_{t-1} \mid q<\kappa_{t}\right] G_{f, t-1}\left(\kappa_{t}\right) N_{f, t-1}
\end{aligned}
$$

Using $\ln (1+x) \approx x$, we can approximate the growth rate by

$$
g=\frac{1}{\sigma-1} \ln \left(1+\int_{f \in \mathcal{M}_{t} \cup \mathcal{X}_{t-1}} g_{f} d f\right) \approx \frac{1}{\sigma-1} \int_{f \in \mathcal{M}_{t} \cup \mathcal{X}_{t-1}} g_{f} d f .
$$

This allows us to define the share of growth coming from firm $f$ as

$$
c_{f}:=\frac{g_{f}}{\int_{f \in \mathcal{M}_{t} \cup \mathcal{X}_{t-1}} g_{f} d f} .
$$

Similarly, we define the contribution of a group of firms $\mathcal{F} \subset\left(\mathcal{M}_{t} \cup \mathcal{X}_{t-1}\right)$ as

$$
c_{\mathcal{F}}:=\frac{\int_{f \in \mathcal{F}} g_{f} d f}{\int_{f \in \mathcal{M}_{t} \cup \mathcal{X}_{t-1}} g_{f} d f} .
$$

\section{Calibration}

In the previous section, we laid out our model of how product innovation contributes to growth. In this section we will describe how to relate the arrival rates and step sizes of innovation to moments we will observe in the data. 
Let $k$ be any non-negative number. For any group of products $\mathcal{P}$, define the $k$ th noncentral moment of market share to be

$$
S_{\mathcal{P} t}^{\{k\}}:=\int_{i \in \mathcal{P}} s_{t}(i)^{k} d i=\int_{i \in \mathcal{P}}\left(\frac{q_{t}(i)}{Q_{t}}\right)^{k(\sigma-1)} d i
$$

Given that $\mathcal{C D}_{f t}$ is the group of products that firm $f$ creatively destroyed between $t-1$ and $t$ with step size $\Delta$,

$$
\begin{aligned}
S_{\mathcal{C} \mathcal{D}_{f t}\{k\}} & =\int_{i \in \mathcal{C} \mathcal{D}_{f t}}\left(\frac{\Delta q_{t-1}(i)}{Q_{t-1}} \frac{Q_{t-1}}{Q_{t}}\right)^{(\sigma-1) k} d i \\
& =\left(\frac{\Delta}{e^{g}}\right)^{(\sigma-1) k} \int_{i \in \mathcal{C} \mathcal{D}_{f t}}\left(\frac{q_{t-1}(i)}{Q_{t-1}}\right)^{(\sigma-1) k} d i \\
& =\left(\frac{\Delta}{e^{g}}\right)^{(\sigma-1) k} \int_{i \in \mathcal{C} \mathcal{D}_{f t}} s_{t-1}(i)^{k} d i \\
& =\delta_{f}\left(\frac{\Delta}{e^{g}}\right)^{(\sigma-1) k} \mathbb{E}_{G_{t-1}}\left(s_{t-1}^{k} \mid q \geq \kappa_{t}\right) N_{t-1}
\end{aligned}
$$

The second-to-last equality holds because, conditional on non-obsolescence, the arrival of creative destruction innovation is independent of $q_{t-1}(i)$.

Using that $\mathcal{N} \mathcal{V}_{f t}$ is the set of new varieties introduced by firm $f$,

$$
S_{\mathcal{N} \mathcal{V}_{f t}}^{\{k\}}=\nu_{f}\left(\frac{V_{f}}{e^{g}}\right)^{(\sigma-1) k} \mathbb{E}_{G_{t-1}}\left(s_{t-1}^{k} \mid q \geq \kappa_{t}\right) N_{t-1}
$$

For a group of firms $\mathcal{F}$, assume they have the same arrival rate and step size for creative destruction and new varieties. Let $\mathcal{E}_{\mathcal{F} t}$ be the set of new products introduced by these firms. Applying the above derivations, we map the $k$ th moments of the employment share of these products to

$$
\begin{aligned}
S_{\mathcal{E}_{\mathcal{F} t}}^{\{k\}} & =S_{\mathcal{N} \mathcal{V}_{\mathcal{F} t}}^{\{k\}}+S_{\mathcal{C} \mathcal{D}_{\mathcal{F} t}}^{\{k\}} \\
\frac{S_{\mathcal{E}_{\mathcal{F} t}}^{\{k\}} / E_{\mathcal{F} t}}{\mathbb{E}_{G_{t-1}}\left(s_{t-1}^{k} \mid q \geq \kappa_{t}\right)} & =\left(\frac{N_{t-1} \nu_{\mathcal{F}}}{E_{\mathcal{F} t}}\left(\frac{V_{\mathcal{F}}}{e^{g}}\right)^{(\sigma-1) k}+\frac{N_{t-1} \delta_{\mathcal{F}}}{E_{\mathcal{F} t}}\left(\frac{\Delta_{\mathcal{F}}}{e^{g}}\right)^{(\sigma-1) k}\right),
\end{aligned}
$$

where $E_{\mathcal{F} t}$ is the number of new products introduced by $\mathcal{F}$. 
Equation (7) says the non-centered $k$ th moment of entering products of firm group $\mathcal{F}$ relative to the non-centered $k$ th moment of all non-obsolete products in the previous period is equal to the average step size of these products' innovation relative to the aggregate growth rate. A group of products that have higher innovation step size has higher relative $k$ th moment. This relationship holds for all $k$. We will use data on $g$ (the aggregate TFP growth rate) and on $S^{k}$ moments for $k=0,1,2,3$, plus the restrictions $V_{\mathcal{F}}>0$ and $\Delta_{\mathcal{F}}>1$, to infer $\nu_{\mathcal{F}}$, $V_{\mathcal{F}}, \delta_{\mathcal{F}}$, and $\Delta_{\mathcal{F}}$.

To estimate the contribution of an incumbent's own innovation, let $\mathcal{P}_{f}$ be the set of products that $f$ produces in both $t-1$ and $t$. The market share growth for these products is

$$
\begin{aligned}
\frac{S_{\mathcal{P}_{f t}}}{S_{\mathcal{P}_{f, t-1}}} & =\frac{\int_{i \in \mathcal{P}} q_{t}(i)^{\sigma-1} d i}{\int_{i \in \mathcal{P}} q_{t-1}(i)^{\sigma-1} d i}\left(\frac{Q_{t-1}}{Q_{t}}\right)^{\sigma-1} \\
& =\frac{\left(1+\widetilde{o}_{f}\left(O_{f}^{\sigma-1}-1\right)\right)\left(1-\widehat{\delta}_{t}\right) \int_{i \in \mathcal{N}_{f, t-1}, q_{t-1}(i) \geq \kappa_{t}} q_{t-1}(i)^{\sigma-1} d i}{\left(1-\widehat{\delta}_{t}\right) \int_{i \in \mathcal{N}_{f, t-1}, q_{t-1}(i) \geq \kappa_{t}} q_{t-1}(i)^{\sigma-1} d i}\left(\frac{Q_{t-1}}{Q_{t}}\right)^{\sigma-1} \\
& =\frac{1+\widetilde{o}_{f t}\left(O_{f}^{\sigma-1}-1\right)}{e^{g(\sigma-1)}} .
\end{aligned}
$$

The market share of the firm's continuing products grows if their realized average quality improvement exceeds the aggregate growth rate.

To estimate the negative contribution of obsolescence, we need to distinguish product exits due to obsolescence from product exits due to creative destruction. The share of firm f's products that it loses to obsolescence or creative destruction is

$$
\frac{x_{f, t-1} N_{t-1}}{N_{f t-1}}=\widehat{\delta}_{t}\left[1-G_{f, t-1}\left(\kappa_{t}\right)\right]+G_{f, t-1}\left(\kappa_{t}\right) .
$$

The share of firm f's sales that belong to products it loses to obsolescence or 
creative destruction is

$$
\begin{aligned}
\frac{S_{\mathcal{X}_{f, t-1}}}{N_{f, t-1} \mathbb{E}_{G_{f, t-1}}\left(s_{t-1}\right)}= & \widehat{\delta}_{t}\left[1-G_{f, t-1}\left(\kappa_{t}\right)\right] \frac{\mathbb{E}_{G_{f, t-1}}\left(s_{t-1} \mid q \geq \kappa_{t}\right)}{\mathbb{E}_{G_{f, t-1}}\left(s_{t-1}\right)} \\
& +G_{f, t-1}\left(\kappa_{t}\right) \frac{\mathbb{E}_{G_{f, t-1}}\left(s_{t-1} \mid q<\kappa_{t}\right)}{\mathbb{E}_{G_{f, t-1}}\left(s_{t-1}\right)}
\end{aligned}
$$

Since creative destruction is random while obsolescence is selected, the share of firm $f$ 's sales belonging to products it loses is smaller than the share of products it loses when it loses some its products to obsolescence. The gap increases with the share of exit that is obsolescence. This relationship helps us to distinguish between creative destruction and obsolescence.

Summing the exit rates across firms and summing the exiting product market shares across firms yield the aggregate exit rate and aggregate market share of exiting products:

$$
\begin{gathered}
x_{t}=\int_{f \in \mathcal{M}_{t-1}}\left[\widehat{\delta}_{t}+\left(1-\widehat{\delta}_{t}\right) G_{f, t-1}\left(\kappa_{t}\right)\right] \frac{N_{f t-1}}{N_{t-1}} d f=\widehat{\delta}_{t}+\left(1-\widehat{\delta}_{t}\right) G_{t-1}\left(\kappa_{t}\right) \\
S_{\mathcal{X}, t-1}=\widehat{\delta}_{t} \int_{i \in N_{t-1} q_{t-1}>\kappa_{t}} s_{t-1}(i) d i+\int_{i \in N_{t-1}}^{\kappa_{t}} s_{t-1}(i) d i .
\end{gathered}
$$

Using equation (11), the exit rate can be rewritten as

$$
\widehat{\delta}_{t}=\frac{x_{t}-G_{t-1}\left(\kappa_{t}\right)}{1-G_{t-1}\left(\kappa_{t}\right)}
$$

Substituting this expression into (12) yields

$$
S_{\mathcal{X}, t-1}=\frac{x_{t}-G_{t-1}\left(\kappa_{t}\right)}{1-G_{t-1}\left(\kappa_{t}\right)} \int_{i \in N_{t-1}, q_{t-1}>\kappa_{t}} s_{t-1}(i) d i+\int_{i \in N_{t-1}}^{\kappa_{t}} s_{t-1}(i) d i .
$$

Holding fixed the exit rate, increasing $\kappa_{t}$ lowers the market share of products exiting due to obsolescence or creative destruction. Instead of randomly replacing a fraction of the producers, making $\kappa_{t}$ positive removes products with the smallest market share. Conditional on $\widehat{\delta}_{t}$, we can use (9) to back out $G_{f, t-1}\left(\kappa_{t}\right)$. 
Since the $t-1$ market share of a firm's continuing products is

$$
\left(1-\widehat{\delta}_{t}\right)\left[1-G_{f, t-1}\left(\kappa_{t}\right)\right] N_{f, t-1} \mathbb{E}_{G_{f, t-1}}\left(s_{t-1} \mid q \geq \kappa_{t}\right),
$$

we can use data on the $t-1$ market share of a firm's continuing products and (10) to infer the market share of obsolete products of firm $f$ and hence calculate the negative contribution to growth from the firm.

We also need $\widehat{Q} / Q$ to calculate the positive contribution of obsolescence. This term can be rewritten as

$$
\frac{N_{t-1}\left[1-G_{t-1}\left(\kappa_{t}\right)\right] \mathbb{E}_{G_{t-1}}\left(s_{t-1} \mid q \geq \kappa_{t}\right)}{1-G_{t-1}\left(\kappa_{t}\right)}
$$

This is none other than the market share of non-obsolete products divided by the share of non-obsolete products. This can be calculated using $\widehat{\delta}_{t}, G_{t-1}\left(\kappa_{t}\right)$ and data on the $t-1$ market share of incumbent firms continuing products.

\subsection{Measuring products}

We calibrate the model to the Longitudinal Business Dynamics (LBD) plantlevel data from the Census Bureau. To make progress, we assume that each plant produces one product and that all new varieties and creative destruction occur through new plants. This enables us to use plant entry and exit to measure the arrival rate of new varieties and creative destruction within firms.

We partition firms in each period into groups. For example, a group can be new firms (age 0) with less the 20 employees. Then the set of new and exiting products by the firm group, $\mathcal{E}_{\mathcal{F}, t}$ and $\mathcal{X}_{\mathcal{F}, t-1}$ respectively, maps into the set of new and exiting plants of the firm group in the data. The set of all products $\mathcal{N}_{t}$ maps to the total set of plants in the data. The arrival rates in the model map to the arrival rate of plants in the data. The market share of products map into to the employment shares of plants in the data. Table 1 summarizes the parameters for calibration and the data targets. 
Table 1: Parameters and data targets

Calibrated parameters

\begin{tabular}{|c|c|}
\hline$\nu_{\mathcal{F}}$ & Arrival rate of $\mathrm{NV}$ by firm group $\mathcal{F}$ \\
\hline$V_{\mathcal{F}}$ & Step size of NV by firm group $\mathcal{F}$ \\
\hline$\delta_{\mathcal{F}}$ & Arrival rate of $\mathrm{CD}$ by firm group $\mathcal{F}$ \\
\hline$\Delta_{\mathcal{F}}$ & Step size of CD by firm group $\mathcal{F}$ \\
\hline$o_{\mathcal{F}}\left(O_{\mathcal{F}}^{\sigma-1}-1\right)$ & Contribution of OI by firm group $\mathcal{F}$ \\
\hline$\kappa$ & Cutoff quality of obsolescence \\
\hline \multirow[t]{2}{*}{$\delta$} & Total rate of creative destruction \\
\hline & Assigned parameter \\
\hline \multirow[t]{2}{*}{$\sigma$} & Elasticity of substitution \\
\hline & Data targets \\
\hline$\frac{\mathcal{E}_{\mathcal{F t}}}{N_{t-1}}$ & \# of new plants by firm group $\mathcal{F}$ \\
\hline$\frac{\mathcal{X}_{\mathcal{F}, t-1}}{N_{t-1}}$ & \# of exiting plants by firm group $\mathcal{F}$ in $t-1$ \\
\hline$S_{\mathcal{E}_{\mathcal{F} t}}$ & employment share of new plants by firm group $\mathcal{F}$ in $t$ \\
\hline$S_{\mathcal{X}_{\mathcal{F}, t-1}}$ & employment share of exiting plants by firm groups $\mathcal{F}$ in $t-1$ \\
\hline$\frac{S_{C_{\mathcal{F} t}}}{S_{C_{\mathcal{F} t-1}}}$ & growth in employment share of continuing plants by firm group $\mathcal{F}$ \\
\hline$S_{\mathcal{E}_{\mathcal{F} t}}^{\{2\}}$ & 2nd moment of employment share of new plants by firm group $\mathcal{F}$ in $t$ \\
\hline$S_{\mathcal{E}_{\mathcal{F} t}}^{\{3\}}$ & 3rd moment of employment share of new plants by firm group $\mathcal{F}$ in $t$ \\
\hline$S_{\mathcal{N}_{t-1}}^{\{k\}}$ & $k$ th moment of employment share of all plants in $t-1$ for $k=0,1,2,3$ \\
\hline$g$ & TFP growth rate \\
\hline
\end{tabular}

Notes: $S_{\mathcal{P} t}^{\{k\}}:=\int_{\mathcal{P}} s_{t}^{k}(i) d i$ 
We carry out calibration in four steps. First, we use (8) plus the change in the employment share of surviving plants to calibrate the own innovation parameters relative to the aggregate growth rate. Given $g$ and $\sigma$, these moments map directly into the composite arrival rate and step size of own innovation by a group of firms: $\left(1+\widetilde{o}_{\mathcal{F}}\left[O_{\mathcal{F}}^{\sigma-1}-1\right]\right) / e^{g(\sigma-1)}$. Second, we calibrate the arrival rate and step size of new varieties and creative destruction $\left\{v_{\mathcal{F}}, \delta_{\mathcal{F}}, \frac{V_{\mathcal{F}}}{e^{g}}, \frac{\Delta_{\mathcal{F}}}{e^{g}}\right\}$ to fit the employment share moments of entering plants in (7) for $k=0,1,2,3 .^{5}$ Third, we sum the calibrated $\delta_{\mathcal{F}}$ across $\mathcal{F}$ to arrive at the aggregate rate of creative destruction $\delta$. We substitute $\delta$ into the aggregate exit rate and exiting plant employment share equations (11) and (13) to back out the rate of obsolescence and the employment share associated with obsolescence. Fourth and finally, we recover the level of step sizes by multiplying the relative step sizes by the measured aggregate TFP growth rate in the data. When a resulting step size violates a minimum boundary condition, for example when it is negative or when $\Delta_{\mathcal{F}}<1$, we set that particular step size to the minimum. We check the validity of our estimates by comparing the fit of the model to the growth rate. ${ }^{6}$

\footnotetext{
${ }^{5}$ We minimize the $L 2$ distance between the $k$ th moments in the data and that implied by (7) for $k=0,1,2,3$. We fit the $k=0$ and $k=1$ moments exactly while giving equal weight to $k=2,3$ moments. Note that (7) by itself is symmetric in the new variety and creative destruction parameters and hence only identifies a pair of values. That is, $\left\{v_{\mathcal{F}}, \delta_{\mathcal{F}}, \frac{V_{\mathcal{F}}}{e^{g}}, \frac{\Delta_{\mathcal{F}}}{e^{g}}\right\}=\left\{\bar{v}_{\mathcal{F}}, \bar{\delta}_{\mathcal{F}}, \frac{\bar{V}_{\mathcal{F}}}{e^{g}}, \frac{\bar{\Delta}_{\mathcal{F}}}{e^{g}}\right\}$ and $\left\{v_{\mathcal{F}}, \delta_{\mathcal{F}}, \frac{V_{f}}{e^{g}}, \frac{\Delta_{\mathcal{F}}}{e^{g}}\right\}=\left\{\bar{\delta}_{\mathcal{F}}, \bar{v}_{\mathcal{F}}, \frac{\bar{\Delta}_{\mathcal{F}}}{e^{g}}, \frac{\bar{V}_{\mathcal{F}}}{e^{g}}\right\}$ generate the same distance. Given the growth rate in the data, restrictions $\Delta_{\mathcal{F}}>1$ and $V_{\mathcal{F}}>0$ break the symmetry and help us choose between the two specifications. This identification does not work if both $\Delta_{\mathcal{F}}$ and $V_{\mathcal{F}}$ exceed 1 . Then we use the aggregate exit rate for identification.

${ }^{6}$ We fit the growth rate by construction when the boundary conditions are not violated. Any gaps between the model-implied growth rate and the growth rate in the data reflect the extent to which we run into corners.
} 


\section{Results}

\subsection{Data}

We use the Longitudinal Business Dynamics (LBD) data from the Census Bureau to calculate moments related to firms. We use the BLS multifactor productivity series to calculate productivity growth. We have access to the LBD data from 1977 to 2013. We partition the firms into age and size bins, where age is the number of years since the first plant of the firm enters the dataset and size is the total employment across all of plants of the firm in the previous year. ${ }^{7}$ The age bins are $0,1-5,6-10$ and $11+$ while the size bins are $0,1-19,20-249,250-999$, 1000-4999, 5000-9999 and 10000+. New firms are in the age 0 and size 0 bin.

To observe firms aged 6+, the earliest year we can start is 1982. Productivity growth in the U.S. experienced a burst of high growth around the 1995 to 2005 period. Hence we divide the years into subperiods before the burst (19821995 , average $1.15 \%$ per year), the burst (1996-2005, average $2.82 \%$ per year) and slowdown (2006-2013, average $1.03 \%$ per year). We target averages of entry, exit, productivity growth and so on over each subperiod.

\subsection{Results: parameter estimates and model fit}

Table 2 presents some of the key data moments from the LBD that we use to estimate estimate arrival rates and step sizes. For conciseness, we average them across all years in the Table. The moments shown include the plant entry rate, the employment share of new plants, and the employment share of continuing plants in the current year relative to their share in the previous year. Size 0 plants are those of new firms.

Table 3 presents the parameters we estimate based on the moments in Table 2. As above, the lower cases are arrival rates and upper cases are step sizes. The

\footnotetext{
${ }^{7}$ We keep ownership of a plant to the firm that first owns the plant. We use employment in the previous year because the current year employment is affected by innovation.
} 
Table 2: Data moments by age-size groups, 1982-2013

\begin{tabular}{|c|c|c|c|c|c|c|}
\hline Age & Size & $\begin{array}{l}\text { Entry } \\
\text { rate }\end{array}$ & $\begin{array}{l}\text { Entry } \\
\text { emp. } \\
\text { share }\end{array}$ & $\frac{S_{E}^{2}}{S_{N}^{2}}$ & $\frac{S_{E}^{3}}{S_{N}^{3}}$ & $\begin{array}{c}\text { Survivor } \\
\text { growth }\end{array}$ \\
\hline 0 & 0 & 8.99 & 3.10 & 2.54 & 3.52 & NA \\
\hline $1-5$ & $1-19$ & 0.12 & 0.06 & 0.04 & 0.05 & 1.15 \\
\hline $1-5$ & $20-249$ & 0.11 & 0.10 & 0.02 & 0.01 & 1.00 \\
\hline $1-5$ & 250-999 & 0.04 & 0.06 & 0.02 & 0.00 & 0.97 \\
\hline $1-5$ & $1 \mathrm{k}-4999$ & 0.03 & 0.04 & 0.04 & 0.02 & 0.95 \\
\hline $1-5$ & $5 k-9999$ & 0.01 & 0.02 & 0.05 & 0.08 & 0.86 \\
\hline $6-10$ & $1-19$ & 0.11 & 0.05 & 0.09 & 0.17 & 0.99 \\
\hline $6-10$ & $20-249$ & 0.07 & 0.06 & 0.02 & 0.02 & 0.91 \\
\hline $6-10$ & 250-999 & 0.04 & 0.04 & 0.01 & 0.00 & 0.90 \\
\hline $6-10$ & $1 \mathrm{k}-4999$ & 0.03 & 0.04 & 0.04 & 0.04 & 0.91 \\
\hline $6-10$ & $5 k-9999$ & 0.01 & 0.02 & 0.01 & 0.01 & 0.89 \\
\hline $6-10$ & $10 \mathrm{k}+$ & 0.01 & 0.02 & 0.04 & 0.05 & 0.89 \\
\hline $11+$ & $1-19$ & 0.26 & 0.18 & 0.39 & 0.74 & 0.98 \\
\hline $11+$ & $20-249$ & 0.18 & 0.14 & 0.07 & 0.10 & 0.91 \\
\hline $11+$ & 250-999 & 0.15 & 0.15 & 0.06 & 0.09 & 0.91 \\
\hline $11+$ & $1 \mathrm{k}-4999$ & 0.23 & 0.26 & 0.19 & 0.21 & 0.91 \\
\hline $11+$ & $5 k-9999$ & 0.13 & 0.14 & 0.15 & 0.22 & 0.91 \\
\hline $11+$ & $10 \mathrm{k}+$ & 0.58 & 0.76 & 0.72 & 0.87 & 0.90 \\
\hline
\end{tabular}

Source: Census LBD. Firm size is the sum of employment across all of its plants. Firm age is the difference between the year of observation minus the birth year of the firm's first plant. "Entry rate" = Number of new plant divided by lagged total number of plants, "Entry emp. share" = Employment share of new plants, “ $\frac{S_{E}^{l}}{S_{N}^{k}}$ ” $=$ new plant $k$ th moment relative to all plants. Units are \%. "Survivor growth" = continuing plants employment share in $t$ over employment share in $t-1$ 
Table provides these statistics by age-size group.

In Table 4 we compare the growth rate in the data to that in our model. When we do not hit any corners, our calibration strategy fits the growth rate by construction. The Table shows that we deviate slightly from the actual growth rates. This is because some parameters hit corner values (such as step sizes being no lower than 1 for creative destruction). Overall, the deviation is small and the model fits the data well. The largest deviation is in the 1982-1986 period.

\subsection{Results: types of innovation}

We first decompose growth by innovation type over the entire 1982-2013 period in Table 5 . We estimate that, on average, $60 \%$ of growth comes from own innovation while new varieties contribute about $27 \%$ and creative destruction the remaining $13 \%$.

When we look at subperiods in Table 6, we see that own innovation generated close to $50 \%$ of growth in the slow-growth periods early on (1982-1995) and more recently (2006-2013), but surged to $70 \%$ of growth in the high-growth middle period (1996-2005). Table 7 shows that all three sources of growth rose in the 1996-2005 period and fell back again afterward. But the bulk of the acceleration (91\%) and the subsequent slowdown (82\%) were due to innovation by incumbent firms on their own products.

\subsection{Results: firm age groups}

Table 8 displays the contribution of each firm age group to growth. Age 0 firms, who are in their first year of operation, contribute almost $1 / 3$ of growth on average despite employing only $3 \%$ of workers. Firms ages $1-5$ and $6-10$ generate similar amounts of growth as their share of employment. Firms age 11+, in contrast, contribute much less growth (41\%) than their share of employment (72\%).

Table 9 looks at growth contributions, in percentage points per year, for firm age groups by subperiod. All age groups contributed to the acceleration of 
Table 3: Calibrated innovation parameter by age-size groups, 1982-2013

\begin{tabular}{|c|c|c|c|c|c|c|}
\hline Age & Size & $v_{f}$ & $V_{f}$ & $\delta_{f}$ & $\Delta_{f}$ & $\tilde{o}_{f}\left(O_{f}-1\right)$ \\
\hline 0 & 0 & 0.081 & 0.602 & 0.009 & 1.184 & 0.000 \\
\hline $1-5$ & $1-19$ & 0.001 & 0.657 & 0.000 & 1.032 & 0.213 \\
\hline $1-5$ & $20-249$ & 0.001 & 0.985 & 0.001 & 1.009 & 0.056 \\
\hline $1-5$ & 250-999 & 0.000 & 1.113 & 0.000 & 1.116 & 0.027 \\
\hline $1-5$ & $1 \mathrm{k}-4999$ & 0.000 & 1.210 & 0.000 & 1.211 & 0.013 \\
\hline $1-5$ & 5k-9999 & 0.000 & 0.916 & 0.000 & 1.351 & 0.000 \\
\hline $6-10$ & $1-19$ & 0.001 & 0.301 & 0.000 & 1.193 & 0.123 \\
\hline $6-10$ & $20-249$ & 0.001 & 0.929 & 0.000 & 1.046 & 0.039 \\
\hline $6-10$ & 250-999 & 0.000 & 1.071 & 0.000 & 1.070 & 0.027 \\
\hline $6-10$ & $1 \mathrm{k}-4999$ & 0.000 & 1.202 & 0.000 & 1.102 & 0.033 \\
\hline $6-10$ & 5k-9999 & 0.000 & 1.297 & 0.000 & 1.184 & 0.014 \\
\hline $6-10$ & $10 \mathrm{k}+$ & 0.000 & 0.956 & 0.000 & 1.259 & 0.017 \\
\hline $11+$ & $1-19$ & 0.002 & 0.028 & 0.001 & 1.232 & 0.104 \\
\hline $11+$ & $20-249$ & 0.001 & 0.943 & 0.001 & 1.222 & 0.036 \\
\hline $11+$ & 250-999 & 0.000 & 0.994 & 0.001 & 1.020 & 0.037 \\
\hline $11+$ & $1 \mathrm{k}-4999$ & 0.000 & 1.183 & 0.002 & 1.059 & 0.037 \\
\hline $11+$ & 5k-9999 & 0.000 & 1.280 & 0.001 & 1.039 & 0.035 \\
\hline $11+$ & $10 \mathrm{k}+$ & 0.000 & 1.164 & 0.006 & 1.119 & 0.029 \\
\hline
\end{tabular}

Source: Census LBD. Firm size is the sum of employment across all of its plants. Firm age is the difference between the year of observation minus the birth year of the firm's first plant. 
Table 4: Fit of model

\begin{tabular}{lcc}
\hline Period & Data $g$ & Model $g$ \\
\hline $1982-1986$ & 1.25 & 1.33 \\
$1987-1995$ & 1.10 & 1.13 \\
$1996-2005$ & 2.82 & 2.83 \\
$2006-2013$ & 1.03 & 1.03 \\
\hline
\end{tabular}

Source: BLS Multifactor Productivity series. Percentage points of average yearly productivity growth within the specified period. Yearly growth is the sum of R\&D and IP contributions to BLS MFP growth, converted into labor augmenting form.

growth from 1982-1995 to 1996-2005, as well as the subsequent deceleration from 2006-2013. But, as displayed in Table 10, older firms drove the speedup (70\%) and the slowdown (59\%). This is still smaller than their share of employment, but much larger than their share of growth in the slow-growth periods. The growth slowdown did not stem from a falling rate of innovation by entering and young firms, but rather by older established firms.

\subsection{Results: firm size groups}

Table 11 displays the contribution of each size group to growth. Size is based on employment in the previous year. Size 0 firms are hence new firms. The Table shows four firm size groups, each with roughly one-fourth of all employment: those with 0-19 employees in the prior year, 20-249 workers, 250-4,999 workers, and 5,000+ workers. The smallest firms account for over $60 \%$ of growth on average. Each of the other size groups account for about one-half as much growth as they do employment.

In Table 12 we show that small firms play an outsized role in all subperiods. All size groups accelerated and decelerated along with aggregate TFP. In fact, 
Table 5: Growth by innovation type, 1982-2013

\begin{tabular}{lccc}
\hline$g$ & $\mathrm{CD}$ & $\mathrm{NV}$ & $\mathrm{OI}$ \\
\hline 1.64 & 0.21 & 0.38 & 1.06 \\
& $13.0 \%$ & $27.2 \%$ & $59.8 \%$ \\
\hline
\end{tabular}

Source: BLS Multifactor Productivity series. Percentage points of average yearly productivity growth within the specified period. Yearly growth is the sum of R\&D and IP contributions to BLS MFP growth, converted into labor augmenting form. All other variables are calculated using the Census LBD. $\mathrm{CD}=$ Creative Destruction, $\mathrm{NV}=$ New Varieties, and $\mathrm{OI}=$ Own Innovation (incumbents improving on their own varieties).

Table 6: Growth by innovation type, subperiods

\begin{tabular}{lcccc}
\hline Period & $g$ & $\mathrm{CD}$ & $\mathrm{NV}$ & OI \\
\hline $1982-1995$ & 1.15 & 0.16 & 0.42 & 0.57 \\
$1996-2005$ & 2.82 & 0.33 & 0.41 & 2.09 \\
$2006-2013$ & 1.03 & 0.13 & 0.28 & 0.62 \\
\hline
\end{tabular}

Source: BLS Multifactor Productivity series. Percentage points of average yearly productivity growth within the specified period. Yearly growth is the sum of R\&D and IP contributions to BLS MFP growth, converted into labor augmenting form. All other variables are calculated using the Census LBD. $\mathrm{CD}=$ Creative Destruction, $\mathrm{NV}=$ New Varieties, and OI = Own Innovation (incumbents improving on their own varieties).

Table 7: Share of the change in TFP growth from innovation types

\begin{tabular}{lcccc}
\hline Period & $\Delta g$ & CD & NV & OI \\
\hline $1982-1995$ vs 1996-2005 & 1.67 & $9.8 \%$ & $-0.5 \%$ & $90.8 \%$ \\
$1996-2005$ vs 2006-2013 & -1.79 & $11.0 \%$ & $7.1 \%$ & $81.9 \%$ \\
\hline
\end{tabular}

Source: BLS Multifactor Productivity series. Percentage points of average yearly productivity growth within the specified period. Yearly growth is the sum of R\&D and IP contributions to BLS MFP growth, converted into labor augmenting form. All other variables are calculated using the Census LBD. CD = Creative Destruction, NV = New Varieties, and OI = Own Innovation (incumbents improving on their own varieties). 
Table 8: Growth by firm age groups, 1982-2013

\begin{tabular}{lcccc}
\hline & Age 0 & Age 1-5 & Age 6-10 & Age 11+ \\
\hline \% of growth & $30.3 \%$ & $18.9 \%$ & $9.7 \%$ & $41.1 \%$ \\
\% of employment & $3.3 \%$ & $13.4 \%$ & $11.2 \%$ & $72.1 \%$ \\
\% of firms & $10.7 \%$ & $31.1 \%$ & $18.5 \%$ & $39.6 \%$ \\
\hline
\end{tabular}

Source: Census LBD. Average growth rate over the entire period is $1.66 \%$. Firm age is the difference between the year of observation minus the birth year of the firm's first plant.

Table 9: Growth by firm age groups, subperiods

\begin{tabular}{lccccc}
\hline Period & $g$ & Age 0 & Age 1-5 & Age 6-10 & Age 11+ \\
\hline $1982-1995$ & 1.15 & 0.45 & 0.25 & 0.10 & 0.35 \\
$1996-2005$ & 2.82 & 0.52 & 0.47 & 0.31 & 1.51 \\
$2006-2013$ & 1.03 & 0.31 & 0.17 & 0.09 & 0.46 \\
\hline
\end{tabular}

Source: BLS Multifactor Productivity series. Percentage points of average yearly productivity growth within the specified period. Yearly growth is the sum of R\&D and IP contributions to BLS MFP growth, converted into labor augmenting form. All other variables are calculated using the Census LBD. Firm age is the difference between the year of observation minus the birth year of the firm's first plant.

Table 10: Share of the change in TFP growth by age group

\begin{tabular}{lccccc}
\hline Period & $\Delta g$ & Age 0 & Age 1-5 & Age 6-10 & Age 11+ \\
\hline $1982-1995$ vs 1996-2005 & 1.67 & $4.4 \%$ & $13.4 \%$ & $12.6 \%$ & $69.6 \%$ \\
$1996-2005$ vs 2006-2013 & -1.79 & $11.8 \%$ & $17.0 \%$ & $12.3 \%$ & $58.9 \%$ \\
\hline
\end{tabular}

Source: BLS Multifactor Productivity series. Percentage points of average yearly productivity growth within the specified period. Yearly growth is the sum of R\&D and IP contributions to BLS MFP growth, converted into labor augmenting form. All other variables are calculated using the Census LBD. Firm age is the difference between the year of observation minus the birth year of the firm's first plant. 
Table 11: Growth by firm size groups, 1982-2013

\begin{tabular}{lcccc}
\hline & $\begin{array}{c}\text { Small } \\
(0-19)\end{array}$ & $\begin{array}{c}\text { Medium } \\
(20-249)\end{array}$ & $\begin{array}{c}\text { Large } \\
(250-4999)\end{array}$ & $\begin{array}{c}\text { Mega } \\
(5000+)\end{array}$ \\
\hline \% of growth & $62.2 \%$ & $15.0 \%$ & $12.2 \%$ & $10.7 \%$ \\
\% of employment & $21.4 \%$ & $26.3 \%$ & $26.9 \%$ & $25.4 \%$ \\
\% of firms & $88.0 \%$ & $11.2 \%$ & $0.8 \%$ & $0.03 \%$ \\
\hline
\end{tabular}

Source: Census LBD. Average growth rate over the entire period is $1.66 \%$. Firm size is the sum of employment across all of its plants.

each size group contributed more or less equally to the speedup and slowdown in Table 13. Thus the performance of mega firms does not directly explain the rise and fall of growth.

Tables 14 and 15 focus on the prominent role played by new firms vs. small young firms - and, for contrast, small old firms. Here we define young as ages 1-5 and small as having 1-19 employees. Small young firms contribute twice as much to growth relative to their share of employment. Older small firms also contribute more to growth than their share of employment, but the difference is much less pronounced. This is reminiscent of the finding by Haltiwanger et al. (2013) that, even conditional on size, young firms grow faster than old firms.

\subsection{Results: innovation type for each age and size group}

We know from Table 8 that new firms contribute disproportionately to growth relative to their employment share. And we know they do no own innovation, by definition. But they do contribute via creative destruction or new varieties? Table 16 says that new firms mostly enter with new varieties. This seems intuitive in that it might be hard for new firms to eclipse existing products. At the other extreme, older firms (age 11+) contribute $40 \%$ of average growth, and 
Table 12: Growth by firm size groups, subperiods

\begin{tabular}{lccccc}
\hline Period & $g$ & $\begin{array}{c}\text { Small } \\
(0-19)\end{array}$ & $\begin{array}{c}\text { Medium } \\
(20-249)\end{array}$ & $\begin{array}{c}\text { Large } \\
(250-4999)\end{array}$ & $\begin{array}{c}\text { Mega } \\
(5000+)\end{array}$ \\
\hline $1982-1995$ & 1.15 & 0.85 & 0.14 & 0.08 & 0.08 \\
$1996-2005$ & 2.82 & 1.30 & 0.55 & 0.51 & 0.46 \\
$2006-2013$ & 1.03 & 0.63 & 0.15 & 0.14 & 0.10 \\
\hline
\end{tabular}

Source: BLS Multifactor Productivity series. Percentage points of average yearly productivity growth within the specified period. Yearly growth is the sum of R\&D and IP contributions to BLS MFP growth, converted into labor augmenting form. All other variables are calculated using the Census LBD. Firm size is the sum of employment across all of its plants.

Table 13: Share of the change in TFP growth by size group

\begin{tabular}{lccccc}
\hline Period & $\Delta g$ & $\begin{array}{c}\text { Small } \\
(0-19)\end{array}$ & $\begin{array}{c}\text { Medium } \\
(20-249)\end{array}$ & $\begin{array}{c}\text { Large } \\
(250-4999)\end{array}$ & $\begin{array}{c}\text { Mega } \\
(5000+)\end{array}$ \\
\hline $1982-1995$ vs 1996-2005 & 1.67 & $27.0 \%$ & $24.7 \%$ & $25.5 \%$ & $22.7 \%$ \\
$1996-2005$ vs 2006-2013 & -1.79 & $37.5 \%$ & $22.2 \%$ & $20.2 \%$ & $20.1 \%$ \\
\hline
\end{tabular}

Source: Census LBD. Firm size is the sum of employment across all of its plants. 
Table 14: Contribution of new, young-small and old-small firms, 1982-2013

\begin{tabular}{lccc}
\hline & New & Young small & Old small \\
\hline \% of growth & 29.9 & 14.1 & 11.6 \\
\% of employment & 3.3 & 6.1 & 8.3 \\
\% of firms & 10.7 & 28.8 & 32.0 \\
\hline
\end{tabular}

Source: Census LBD. "New" = age 0, "Young" = age 1-5 and "Small" = employment 1-19. Firm age is the difference between the year of observation minus the birth year of the firm's first plant. Firm size is the sum of employment across all of its plants.

Table 15: Contribution of new, young-small, and old-small firms by period

\begin{tabular}{lccc}
\hline Period & New & Young small & Old small \\
\hline $1982-1995$ & 37.9 & 17.1 & 10.8 \\
$1996-2005$ & 18.5 & 10.9 & 11.3 \\
$2006-2013$ & 30.1 & 12.8 & 13.2 \\
\hline
\end{tabular}

Source: Census LBD. "New" = age 0, "Young" = age 1-5 and "Small" = employment 1-19. Firm age is the difference between the year of observation minus the birth year of the firm's first plant. Firm size is the sum of employment across all of its plants. 
Table 16: Growth by innovation type for each age group, 1982-2013

\begin{tabular}{lccccc}
\hline Age & CD & NV & OI & Total & \% of Emp \\
\hline 0 & 7.2 & 23.0 & 0.0 & 30.3 & 3.3 \\
$1-5$ & 0.7 & 1.2 & 17.1 & 18.9 & 13.4 \\
$6-10$ & 0.7 & 0.9 & 8.1 & 9.7 & 11.2 \\
$11+$ & 4.4 & 2.1 & 34.6 & 41.1 & 72.1 \\
\hline
\end{tabular}

Source: Census LBD. CD = Creative Destruction, NV = New Varieties, and OI = Own Innovation (incumbents improving on their own varieties). Firm age is the difference between the year of observation minus the birth year of the firm's first plant.

Table 17: Growth contribution by innovation type and age groups, subperiods

\begin{tabular}{llccccc}
\hline Period & Age & CD & NV & OI & Total & \% of Emp \\
\hline $1982-1995$ & 0 & 7.8 & 31.0 & 0.0 & 38.8 & 3.9 \\
& $1-5$ & 0.9 & 1.9 & 19.0 & 21.8 & 15.5 \\
& $6-10$ & 0.4 & 1.5 & 7.2 & 9.1 & 12.1 \\
& $11+$ & 5.1 & 1.9 & 23.4 & 30.4 & 68.5 \\
$1996-2005$ & 0 & 5.1 & 13.4 & 0.0 & 18.5 & 3.1 \\
& $1-5$ & 0.8 & 0.1 & 15.9 & 16.8 & 12.7 \\
& $6-10$ & 1.0 & 0.6 & 9.5 & 11.2 & 11.1 \\
& $11+$ & 4.6 & 0.4 & 48.5 & 53.5 & 73.0 \\
& 0 & 8.9 & 21.2 & 0.0 & 30.1 & 2.5 \\
& $1-5$ & 0.1 & 1.2 & 15.3 & 16.6 & 10.6 \\
& $6-10$ & 0.7 & 0.4 & 8.0 & 9.1 & 9.5 \\
& $11+$ & 2.9 & 4.5 & 36.9 & 44.2 & 77.3 \\
\hline
\end{tabular}

Source: Census LBD. CD = Creative Destruction, NV = New Varieties, and OI = Own Innovation (incumbents improving on their own varieties). Firm age is the difference between the year of observation minus the birth year of the firm's first plant. 
more than $3 / 4$ of this comes from their efforts to improve their own products. They do comparatively little creative destruction and variety creation. The picture that emerges is that old firms improve their own products and new firms introduce new varieties. Creative destruction is more evenly split among entrants and older firms.

Table 17 breaks the growth contribution of each age group into each innovation type for each subperiod. Old firms were evidently responsible for the bulk of the growth acceleration and slowdown. In Table 18 we assess the type of innovation pursued by each firm size group. For every group other than entrants — from firms with 1-19 up through 10,000 or more employees - their main source of growth is own innovation. Table 19, which gives contributions by innovation type and size groups in subperiods, reveals some interesting patterns. The surge in own innovation from 1996-2005 occurred in firms with 20 or more employees. Even though young firms typically do a lot of own innovation, this increased relatively little in this fast-growth subperiod. 
Table 18: Growth contribution by innovation type for each size group, 1982-2013

\begin{tabular}{lccccc}
\hline Size & CD & NV & OI & Total & \% of Emp \\
\hline 0 & 7.2 & 23.0 & 0.0 & 30.3 & 3.3 \\
$1-19$ & 1.3 & 0.6 & 30.0 & 31.9 & 18.1 \\
$20-249$ & 0.1 & 2.8 & 12.1 & 15.0 & 26.3 \\
$250-999$ & 0.4 & 0.5 & 4.9 & 5.8 & 12.8 \\
$1 \mathrm{k}-4999$ & 0.8 & 0.1 & 5.5 & 6.4 & 14.1 \\
$5 \mathrm{k}-9999$ & 0.5 & 0.1 & 1.9 & 2.5 & 5.8 \\
$10 \mathrm{k}+$ & 2.6 & 0.1 & 5.5 & 8.2 & 19.6 \\
\hline
\end{tabular}

Source: Census LBD. CD = Creative Destruction, NV = New Varieties, and OI = Own Innovation (incumbents improving on their own varieties). Firm size is the sum of employment across all of its plants. 
Table 19: Growth contribution by innovation type and size groups, subperiods

\begin{tabular}{|c|c|c|c|c|c|c|}
\hline Period & Size & CD & $\mathrm{NV}$ & OI & Total & $\%$ of Emp \\
\hline \multirow[t]{7}{*}{ 1982-1995 } & 0 & 7.8 & 31.0 & 0.0 & 38.8 & 3.9 \\
\hline & $1-19$ & 0.5 & 1.2 & 33.5 & 35.2 & 19.0 \\
\hline & $20-249$ & 0.1 & 3.7 & 8.1 & 11.9 & 25.8 \\
\hline & 250-999 & 0.5 & 0.0 & 2.5 & 3.0 & 12.0 \\
\hline & $1 \mathrm{k}-4999$ & 1.0 & 0.1 & 2.9 & 4.0 & 13.5 \\
\hline & 5k-9999 & 0.7 & 0.1 & 0.8 & 1.5 & 5.8 \\
\hline & $10 \mathrm{k}+$ & 3.6 & 0.2 & 1.8 & 5.6 & 19.9 \\
\hline \multirow[t]{7}{*}{ 1996-2005 } & 0 & 5.1 & 13.4 & 0.0 & 18.5 & 3.1 \\
\hline & $1-19$ & 1.8 & 0.1 & 25.9 & 27.8 & 17.8 \\
\hline & $20-249$ & 0.1 & 0.6 & 18.8 & 19.5 & 26.9 \\
\hline & 250-999 & 0.6 & 0.0 & 7.7 & 8.4 & 13.2 \\
\hline & $1 \mathrm{k}-4999$ & 1.1 & 0.0 & 8.5 & 9.6 & 14.3 \\
\hline & 5k-9999 & 0.3 & 0.3 & 3.0 & 3.6 & 5.8 \\
\hline & $10 \mathrm{k}+$ & 2.6 & 0.1 & 10.0 & 12.7 & 18.9 \\
\hline \multirow[t]{7}{*}{ 2006-2013 } & 0 & 8.9 & 21.2 & 0.0 & 30.1 & 2.5 \\
\hline & $1-19$ & 2.2 & 0.2 & 28.9 & 31.4 & 17.0 \\
\hline & $20-249$ & 0.1 & 3.9 & 10.7 & 14.7 & 26.3 \\
\hline & 250-999 & 0.1 & 1.8 & 5.4 & 7.3 & 13.4 \\
\hline & $1 \mathrm{k}-4999$ & 0.4 & 0.0 & 6.3 & 6.7 & 15.0 \\
\hline & 5k-9999 & 0.2 & 0.0 & 2.5 & 2.7 & 5.8 \\
\hline & $10 \mathrm{k}+$ & 0.7 & 0.1 & 6.3 & 7.1 & 19.9 \\
\hline
\end{tabular}

Source: Census LBD. CD = Creative Destruction, NV = New Varieties, and OI = Own Innovation (incumbents improving on their own varieties). Firm size is the sum of employment across all of its plants. 


\subsection{Obsolescence}

As we described, our model features exit of the lowest quality products each period. In the data, we observe both the exit rate of plants and the average employment of exiting plants. We can calculate these moments separately by firm age and size, as well.

How do we distinguish the rate of creative destruction - which also produces plant exit - from obsolescence? The key is our assumption that creative destruction is undirected, or just as likely for how and high quality products. For this reason, creatively destroyed plants should be of average size. In the data, in contrast, exiting plants are smaller on average than plants operating in the previous year. As a result, we can infer the the fraction of exiting plants from the size and number of plants in the left tail plus the difference between the average size of exiting plants and all plants.

From the point of view of our accounting, these are "lost varieties" which detract from growth. ${ }^{8}$ We do not subtract this obsolescence from any particular innovation channel, but instead from all channels in equal proportion to their contribution to growth. Table 20 provides our estimates of the fraction of plants exiting due to obsolescence, and their share of employment. We infer that 3-4\% of employment is at the $9-10 \%$ of plants who will exit due to obsolescence in the next year. These rates show no clear trend across subperiods.

Tables 22 and 23 trace the obsolescence to plants of varying ages and sizes. There is no obsolescence among entering plants (age $=0$, size $=0$ ) by construction. Roughly one-half of obsolescence occurs at plants $6+$ years old, and the other half at plants 1-5 years old. Not surprisingly, most of obsolescence involves the smallest plants, with 1-19 employees.

\footnotetext{
${ }^{8} \mathrm{~A}$ structural model might feature overhead labor to explain such exit.
} 
Table 20: Obsolescence

\begin{tabular}{cccc}
\hline Period & \% of Emp & \% of Plants & contrib OB \\
\hline $1982-1995$ & 4.15 & 10.34 & -1.06 \\
$1996-2005$ & 2.93 & 8.53 & -0.29 \\
$2006-2013$ & 2.83 & 9.01 & -0.84 \\
\hline
\end{tabular}

Source: Census LBD. Entries are percent of all employment or percent of the overall number of plants.

\section{Further results and future applications}

\subsection{Treating all $0-5$ year old firms as entrants}

In Table 16, we show that new firms mostly contribute by introducing new varieties, while young firms aged 1 to 5 contribute mostly through own-innovation. In the presence of adjustment costs, however, what we infer as own innovation by young firms may actually be the dynamics of accumulating inputs and acquiring customers. We therefore check the robustness of our findings to treating age 1 to 5 firms as new firm. Doing so reinterprets the growth of young firms to come from creative destruction and new varieties rather than own innovation. Table 21 displays the results. We find that new firms (aged 0 to 5) now account for 49 percent of all growth, up from 30 percent. The contribution of own innovation falls from 60 percent to 43 percent. That from creative destruction increases from 13 to 17 percent, while the contribution from new varieties increases from 27 to 40 percent.

\subsection{Contribution of superstar firms}

One advantage of our method is that it can be used to quantify the contribution of individual firms to aggregate growth. Since we cannot reveal the identity 
Table 21: Treating all 0-5 year old firms as entrants

\begin{tabular}{lccccc}
\hline Age & CD & NV & OI & Total & \% of Emp \\
\hline $0-5$ & 12.0 & 37.2 & 0.0 & 49.2 & 16.7 \\
$6-10$ & 0.7 & 0.9 & 8.1 & 9.7 & 11.2 \\
$11+$ & 4.4 & 2.1 & 34.6 & 41.1 & 72.1 \\
\hline Total & 17.1 & 40.2 & 42.7 & & \\
\hline
\end{tabular}

Source: Census LBD. CD = Creative Destruction, NV = New Varieties, and OI = Own Innovation (incumbents improving on their own varieties). Firm age is the difference between the year of observation minus the birth year of the firm's first plant. Entries are percent of all employment or percent of the overall number of plants.

of individual firms in the Census data, we apply our method to the National Establishment Time-Series (NETS) Database, which ranges from 1990 to 2014. The unit of observation is an establishment. As in the Census, we define entry of an establishment as the first time an establishment is observed in a location in the data. We define exit as when an establishment ceases to operate in a location. For each establishment, we observe its employment and, mostly importantly, the identity of its headquarter plant and therefore its firm identity. ${ }^{9}$ Finally, we restrict the time period to 1996-2005 because this period is comparable to the high growth period in our calculations with the Census data, and the post-2005 NETS data displays large swings in the entry and exit of plants that are inconsistent with the Census data.

As a demonstration of our method, we used the NETS 1996-2005 data to calculate the contribution of Amazon and Walmart. We find that, while both companies grew during this window, their contribution to overall growth was quite modest. Amazon accounted for only $0.0041 \%$ of growth (less than $1 \%$

\footnotetext{
${ }^{9}$ We do not use NETS sales data because it is imputed at the establishment level from establishment employment and firm-level sales. Also, like what we did for the Census data, we remove mechanical effects from mergers and acquisitions by defining the owner of an establishment as the firm that owns the establishment at the time of entry.
} 
of all growth), while Walmart contributed $0.80 \%$ (closer to $1 \%$ of all growth, or over 2 basis points of annual TFP growth). Nonetheless, Amazon's contribution was three times its employment share, while Walmart's growth contribution was twice its employment share.

\subsection{Future applications}

Our innovation accounting is distinct from gross job creation, gross job destruction, or net job creation. It can therefore be helpful to contrast our results to these statistics, which have garnered substantial attention. For example, young fast-growing firms - so-called "gazelles" - are responsible for a notable fraction of gross and net job creation. How much growth do they generate on average? And how much of gross job destruction is due to creative destruction, as opposed to obsolescence?

We could carry out several important robustness checks. We could follow Aghion, Bergeaud, Boppart, Klenow and Li (2019) and distinguish between measured and true growth. They argue that measured growth mostly captures own innovation by incumbents, and misses most growth from new varieties and creative destruction. We could re-estimate parameters under this hypothesis.

For manufacturing the Census has data on revenue and capital as well as labor at the plant level. Thus for manufacturing we could back out underlying productivity, rather than assume sales are proportional to employment and the absence of adjustment costs and distortions. We could apply our innovation accounting on directly to this underlying productivity measure, and see how our inference compares to that with employment alone.

Future work could implement our approach to assess the contribution of locations (states, cities) to aggregate growth. It could also decompose growth within industries such ICT or retail. One could also look at which cohorts of entering firms have contributed the most to growth. Our method does not mechanically count firm employment growth due to mergers and acquisitions as 
contributing to growth. But one could investigate whether targets of M\&A activity become more innovative after they are taken over. This could obtain results at odd with existing analyses, which focus on revenue productivity.

\section{Conclusion}

We exploited U.S. Census data on employment at plants across all firms in the nonfarm business sector from 1982-2013. We traced aggregate TFP growth to the innovation efforts of firms by their size and age. We arrived at three main findings. First, young firms (ages 0 to 5) generate one-half of growth, roughly three times more than their share of employment might suggest. Second, large firms are at the other end of the spectrum, contributing notably less to growth than their share of employment. Third, a majority of growth takes the form of quality improvements by incumbents on their own products. New varieties and creative destruction contribute less, but are still important. Such own innovation accounts for the bulk of the growth speedup and slowdown in the middle of our sample.

Our study comes with many caveats that we hope future work, with better data, can address. We used a plant as a proxy for a product. With more detailed data on products sold within plants, this can be relaxed. See, for example, Bernard, Redding and Schott (2010) on manufacturing and Hottman et al. (2016) on packaged consumer goods.

We gauged a plant's size by its employment rather than its sales and combined plants with a CES aggregator. Though they are highly correlated in manufacturing, where we can see both, some innovation surely tilts toward capital and away from labor (automation). And a richer analysis could place industries into CES nests and entertain non-CES aggregation.

Even under CES aggregation, a plant's sales are a perfect reflection of its underlying productivity only in the absence of adjustment costs and distortions such as markups, markdowns, and financial frictions. Adjustment costs could 
include those for inputs, or to acquiring a customer base. We could be overstating the importance of young firms for innovation (overall and by incumbents on their own products) if their fast growth is due, in part, to adjusting their inputs and stock of customers.

We assumed that creative destruction was untargeted. That is, higher quality products are just as likely to be creatively destroyed as lower quality products. One can think of a priori reasons why creative destruction would target higher quality products (more sales to gain) or lower quality products (perhaps easier to improve upon).

We made the arrival rates and step sizes of innovation depend only on the size and age of innovating firms . Studies such as Akcigit and Kerr (2018) have argued that innovation by new and young firms generates bigger spillovers. This would reinforce our conclusion that younger firms punch above their weight class in terms of growth.

Our innovation accounting is silent on the determinants of arrival rates and step sizes of innovation. Knowing the structural parameters that drive these variables is vital for drawing policy lessons. See Atkeson and Burstein (2019). One key question for future research is whether creative destruction is a strategic complement or substitute for own innovation by incumbents. If they are substitutes, as in Peters (2019) and Akcigit and Ates (2019), then a falling rate of creative destruction may be offset by a rising rate of own innovation. If they are complements, however, then perhaps the threat of creative destruction spurs innovative efforts by incumbents. This is the spirit of the model in Aghion, Bloom, Blundell, Griffith and Howitt (2005) in which the threat of being overtaken by followers or entrants leads to more innovation by leaders. 


\title{
8. Appendix with Extra Figures and Tables
}

\author{
Figure 3: Microsoft
}

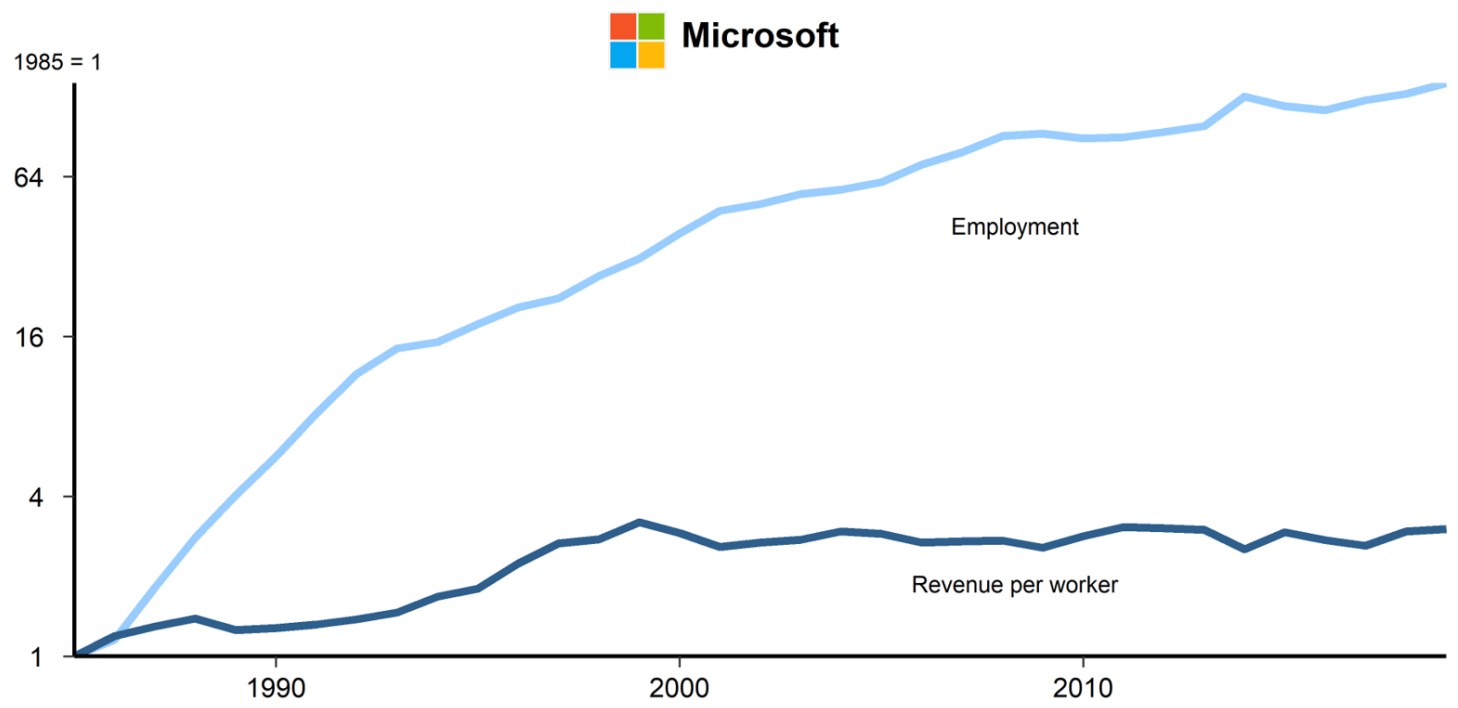

Source: WRDS Compustat and BEA Table 1.1.9. Revenue per worker = "REVT / (GDP Deflator $\mathrm{x}$ EMP)", Employment = "EMP" and Year = "FYEAR". The graph displays revenue per worker and employment relative to the first year when both series are available for the firm. 
Figure 4: Google

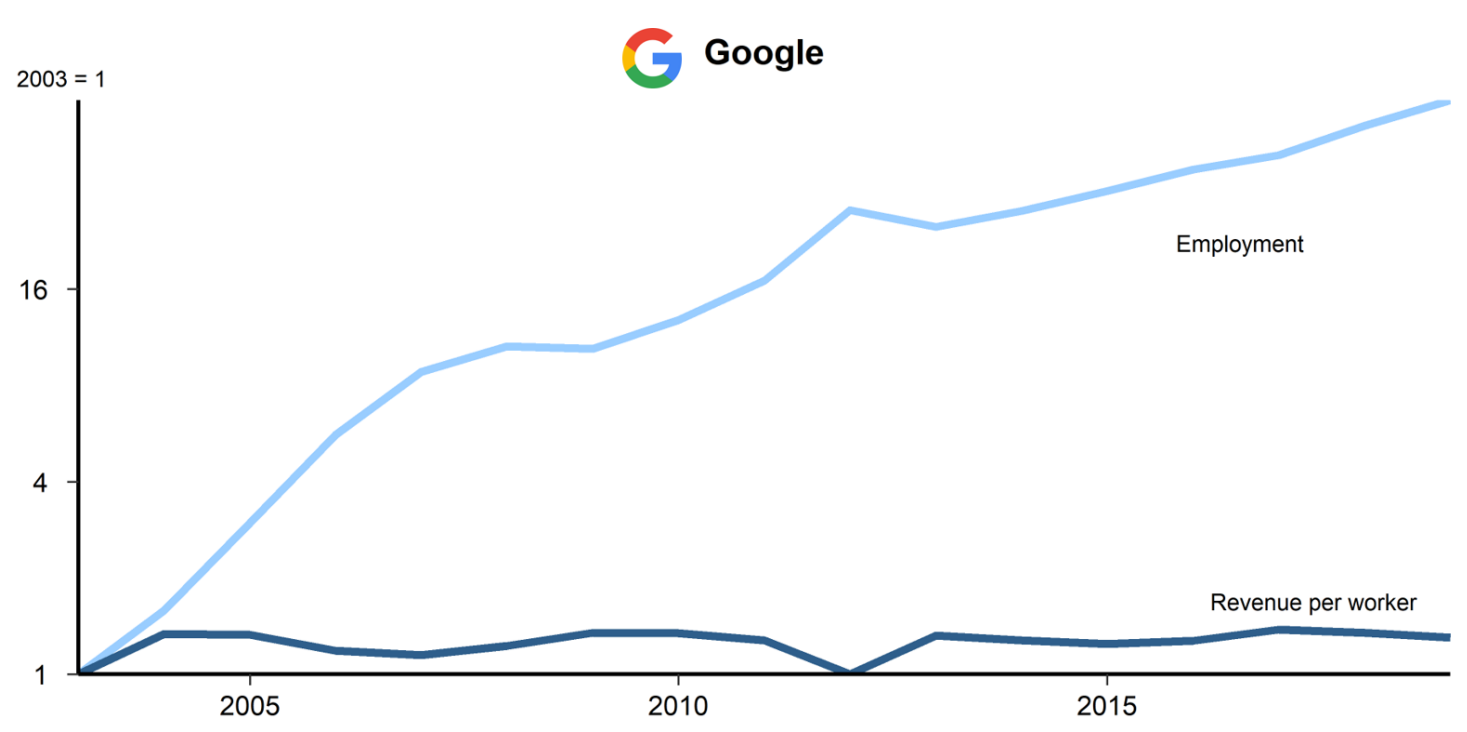

Source: WRDS Compustat and BEA Table 1.1.9. Revenue per worker = "REVT / (GDP Deflator $\mathrm{x}$ EMP)", Employment = "EMP" and Year = "FYEAR". The graph displays revenue per worker and employment relative to the first year when both series are available for the firm.

Figure 5: Facebook

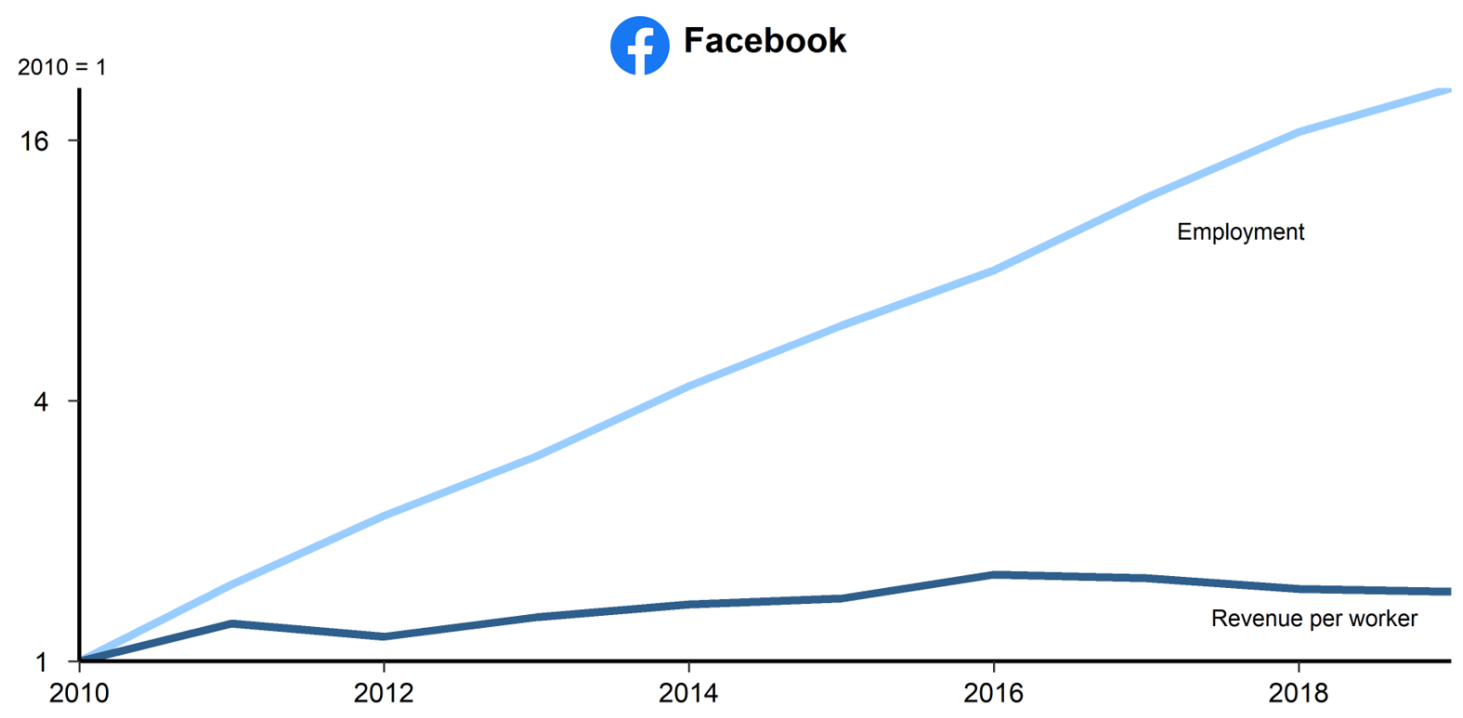

Source: WRDS Compustat and BEA Table 1.1.9. Revenue per worker = "REVT / (GDP Deflator $\mathrm{x}$ EMP)", Employment = "EMP" and Year = "FYEAR". The graph displays revenue per worker and employment relative to the first year when both series are available for the firm. 
Figure 6: Apple

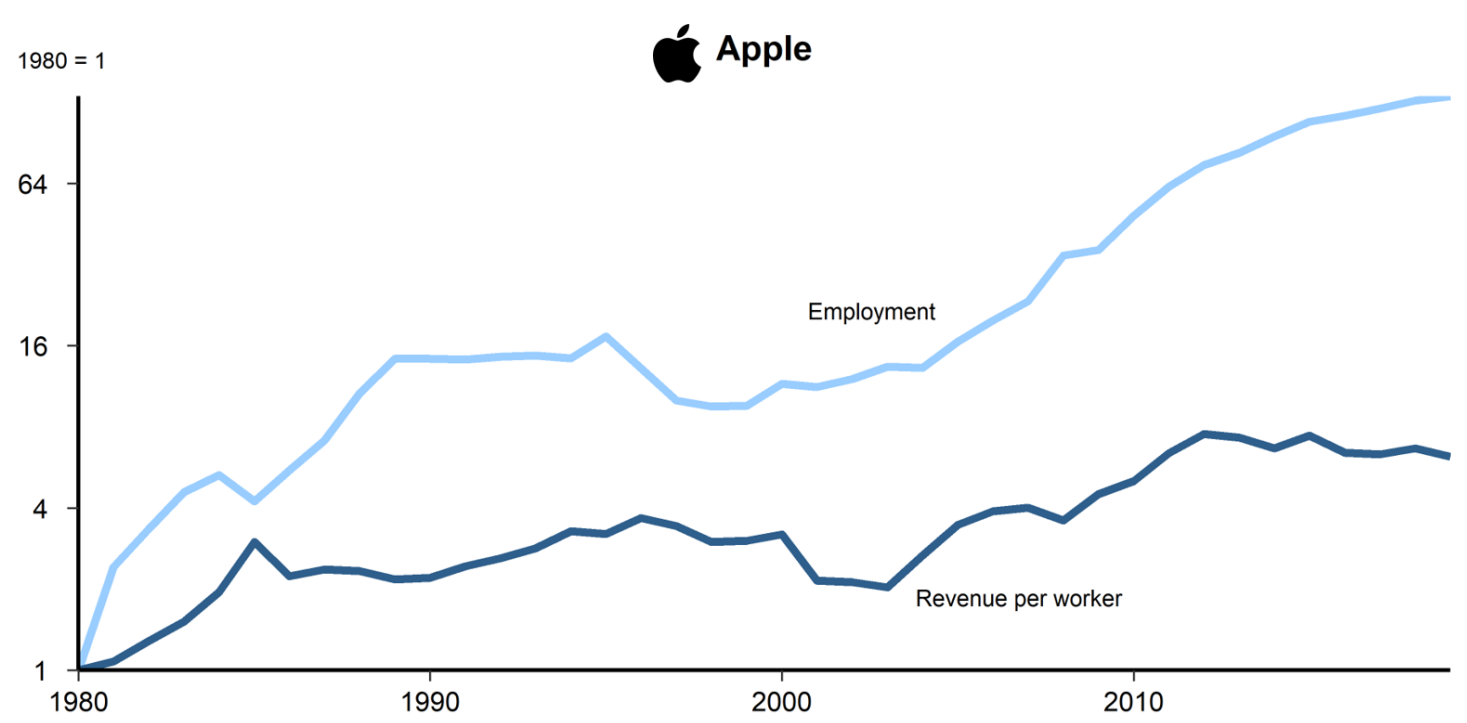

Source: WRDS Compustat and BEA Table 1.1.9. Revenue per worker = "REVT / (GDP Deflator $\mathrm{x}$ EMP)", Employment = "EMP" and Year = "FYEAR". The graph displays revenue per worker and employment relative to the first year when both series are available for the firm.

Figure 7: Starbucks

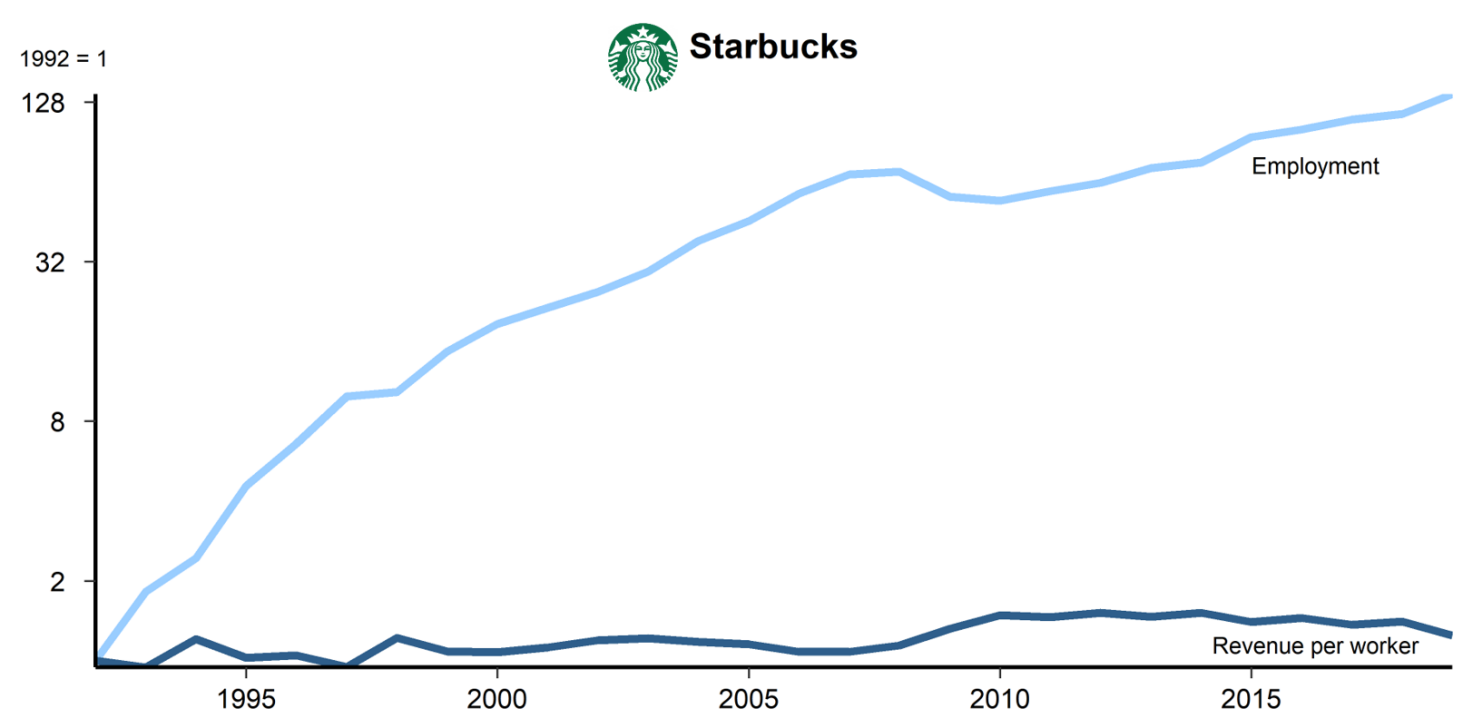

Source: WRDS Compustat and BEA Table 1.1.9. Revenue per worker = "REVT / (GDP Deflator $\mathrm{x}$ EMP)", Employment = "EMP" and Year = "FYEAR". The graph displays revenue per worker and employment relative to the first year when both series are available for the firm. 
Table 22: Obsolescence by age groups

\begin{tabular}{llccc}
\hline Period & Age & \% of Emp & \% of Plants & contrib OB \\
\hline $1982-1995$ & 0 & 0.0 & 0.0 & 0.0 \\
& $1-5$ & 2.1 & 5.8 & -0.5 \\
$1996-2005$ & $6-10$ & 0.7 & 1.7 & -0.2 \\
& $11+$ & 1.3 & 2.9 & -0.3 \\
& $1-5$ & 0.0 & 0.0 & 0.0 \\
& $6-10$ & 1.3 & 4.4 & -0.1 \\
& $11+$ & 0.5 & 1.4 & -0.0 \\
& 0 & 1.1 & 2.8 & -0.1 \\
& $1-5$ & 0.0 & 0.0 & 0.0 \\
& $6-10$ & 1.5 & 4.6 & -0.4 \\
& $11+$ & 0.6 & 1.5 & -0.2 \\
& $1006-2013$ & 0.8 & 2.9 & -0.2 \\
\hline
\end{tabular}

Source: Census LBD. Firm age is the difference between the year of observation minus the birth year of the firm's first plant. Units are percent of total employment or total number plants 
Table 23: Obsolescence by size groups

\begin{tabular}{|c|c|c|c|c|}
\hline Period & Size & $\%$ of Emp & $\%$ of Plants & contrib OB \\
\hline \multirow[t]{7}{*}{ 1982-1995 } & 0 & 0.0 & 0.0 & 0.0 \\
\hline & $1-19$ & 2.6 & 9.2 & -0.7 \\
\hline & $20-249$ & 0.9 & 0.3 & -0.2 \\
\hline & 250-999 & 0.1 & 0.1 & -0.0 \\
\hline & $1 \mathrm{k}-4999$ & 0.1 & 0.2 & -0.0 \\
\hline & 5k-9999 & 0.1 & 0.1 & -0.0 \\
\hline & $10 \mathrm{k}+$ & 0.4 & 0.4 & -0.1 \\
\hline \multirow[t]{7}{*}{ 1996-2005 } & 0 & 0.0 & 0.0 & 0.0 \\
\hline & $1-19$ & 1.5 & 7.4 & -0.2 \\
\hline & $20-249$ & 0.6 & 0.2 & -0.1 \\
\hline & 250-999 & 0.1 & 0.1 & -0.0 \\
\hline & $1 \mathrm{k}-4999$ & 0.1 & 0.2 & -0.0 \\
\hline & $5 k-9999$ & 0.1 & 0.1 & -0.0 \\
\hline & $10 \mathrm{k}+$ & 0.5 & 0.6 & -0.0 \\
\hline \multirow[t]{7}{*}{ 2006-2013 } & 0 & 0.0 & 0.0 & 0.0 \\
\hline & $1-19$ & 2.0 & 8.3 & -0.6 \\
\hline & $20-249$ & 0.7 & 0.1 & -0.2 \\
\hline & 250-999 & 0.0 & 0.0 & 0.0 \\
\hline & $1 \mathrm{k}-4999$ & 0.0 & 0.1 & 0.0 \\
\hline & $5 k-9999$ & 0.0 & 0.1 & 0.0 \\
\hline & $10 \mathrm{k}+$ & 0.2 & 0.5 & -0.0 \\
\hline
\end{tabular}

Source: Census LBD. Firm size is the sum of employment across all of its plants. Units are percent of total employment or total number plants 
Table 24: Contribution by age-size groups, 1982-1995

\begin{tabular}{|c|c|c|c|c|c|c|}
\hline Size & Age & $\mathrm{CD}$ & $\mathrm{NV}$ & OI & Total & $\%$ of Emp \\
\hline 0 & 0 & 7.6 & 30.3 & 0.0 & 37.9 & 3.9 \\
\hline $1-19$ & $1-5$ & 0.1 & 0.7 & 16.4 & 17.1 & 7.2 \\
\hline $1-19$ & $6-10$ & 0.3 & 0.4 & 6.1 & 6.8 & 4.2 \\
\hline $1-19$ & $11+$ & 0.4 & 0.0 & 10.4 & 10.8 & 7.7 \\
\hline $20-249$ & $1-5$ & 0.0 & 1.1 & 2.2 & 3.4 & 5.6 \\
\hline $20-249$ & $6-10$ & 0.0 & 0.8 & 1.3 & 2.1 & 4.6 \\
\hline $20-249$ & $11+$ & 0.1 & 1.6 & 4.4 & 6.1 & 15.5 \\
\hline 250-999 & $1-5$ & 0.3 & 0.0 & 0.0 & 0.3 & 1.3 \\
\hline 250-999 & $6-10$ & 0.2 & 0.0 & 0.0 & 0.2 & 1.4 \\
\hline 250-999 & $11+$ & 0.1 & 0.0 & 2.5 & 2.6 & 9.3 \\
\hline $1 \mathrm{k}-4999$ & $1-5$ & 0.2 & 0.0 & 0.0 & 0.2 & 0.9 \\
\hline $1 \mathrm{k}-4999$ & $6-10$ & 0.4 & 0.0 & 0.2 & 0.6 & 1.1 \\
\hline $1 \mathrm{k}-4999$ & $11+$ & 0.6 & 0.1 & 2.6 & 3.4 & 11.5 \\
\hline 5k-9999 & $1-5$ & 0.2 & 0.0 & 0.0 & 0.2 & 0.5 \\
\hline 5k-9999 & $6-10$ & 0.2 & 0.0 & 0.0 & 0.2 & 0.3 \\
\hline 5k-9999 & $11+$ & 0.4 & 0.0 & 0.7 & 1.2 & 5.1 \\
\hline $10 \mathrm{k}+$ & $6-10$ & 1.4 & 0.0 & 0.0 & 1.4 & 0.4 \\
\hline $10 \mathrm{k}+$ & $11+$ & 3.5 & 0.2 & 1.7 & 5.4 & 19.5 \\
\hline
\end{tabular}

Source: Census LBD. CD = Creative Destruction, NV = New Varieties, and OI = Own Innovation (incumbents improving on their own varieties). Firm size is the sum of employment across all of its plants. Firm age is the difference between the year of observation minus the birth year of the firm's first plant. 
Table 25: Contribution by age-size groups, 1996-2005

\begin{tabular}{|c|c|c|c|c|c|c|}
\hline Size & Age & $\mathrm{CD}$ & $\mathrm{NV}$ & OI & Total & $\%$ of Emp \\
\hline 0 & 0 & 5.1 & 13.4 & 0.0 & 18.5 & 3.1 \\
\hline $1-19$ & $1-5$ & 0.0 & 0.1 & 10.8 & 10.9 & 5.6 \\
\hline $1-19$ & $6-10$ & 0.4 & 0.0 & 5.1 & 5.5 & 3.6 \\
\hline $1-19$ & $11+$ & 1.3 & 0.0 & 10.0 & 11.3 & 8.5 \\
\hline $20-249$ & $1-5$ & 0.1 & 0.0 & 4.1 & 4.2 & 4.6 \\
\hline $20-249$ & $6-10$ & 0.0 & 0.6 & 2.9 & 3.5 & 4.2 \\
\hline $20-249$ & $11+$ & 0.0 & 0.0 & 11.8 & 11.8 & 18.0 \\
\hline $250-999$ & $1-5$ & 0.2 & 0.0 & 0.7 & 0.9 & 1.2 \\
\hline 250-999 & $6-10$ & 0.1 & 0.0 & 0.7 & 0.8 & 1.3 \\
\hline 250-999 & $11+$ & 0.3 & 0.0 & 6.4 & 6.6 & 10.7 \\
\hline $1 \mathrm{k}-4999$ & $1-5$ & 0.3 & 0.0 & 0.3 & 0.6 & 0.8 \\
\hline $1 \mathrm{k}-4999$ & $6-10$ & 0.2 & 0.0 & 0.6 & 0.8 & 1.1 \\
\hline $1 \mathrm{k}-4999$ & $11+$ & 0.6 & 0.0 & 7.7 & 8.2 & 12.4 \\
\hline $5 k-9999$ & $1-5$ & 0.2 & 0.0 & 0.0 & 0.2 & 0.4 \\
\hline $5 k-9999$ & $6-10$ & 0.1 & 0.0 & 0.1 & 0.2 & 0.3 \\
\hline $5 k-9999$ & $11+$ & 0.1 & 0.3 & 2.9 & 3.3 & 5.0 \\
\hline $10 \mathrm{k}+$ & $6-10$ & 0.2 & 0.0 & 0.2 & 0.4 & 0.5 \\
\hline $10 \mathrm{k}+$ & $11+$ & 2.4 & 0.1 & 9.8 & 12.3 & 18.4 \\
\hline
\end{tabular}

Source: Census LBD. CD = Creative Destruction, NV = New Varieties, and OI = Own Innovation (incumbents improving on their own varieties). Firm size is the sum of employment across all of its plants. Firm age is the difference between the year of observation minus the birth year of the firm's first plant. 
Table 26: Contribution by age-size groups, 2006-2013

\begin{tabular}{|c|c|c|c|c|c|c|}
\hline Size & Age & $\mathrm{CD}$ & $\mathrm{NV}$ & OI & Total & $\%$ of Emp \\
\hline 0 & 0 & 8.9 & 21.2 & 0.0 & 30.1 & 2.5 \\
\hline $1-19$ & $1-5$ & 0.0 & 0.2 & 12.6 & 12.8 & 4.8 \\
\hline $1-19$ & $6-10$ & 0.2 & 0.0 & 5.2 & 5.4 & 3.2 \\
\hline $1-19$ & $11+$ & 2.1 & 0.0 & 11.1 & 13.2 & 9.0 \\
\hline $20-249$ & $1-5$ & 0.0 & 0.9 & 2.4 & 3.3 & 4.0 \\
\hline $20-249$ & $6-10$ & 0.1 & 0.4 & 1.8 & 2.3 & 3.7 \\
\hline $20-249$ & $11+$ & 0.0 & 2.5 & 6.6 & 9.1 & 18.6 \\
\hline 250-999 & $1-5$ & 0.0 & 0.0 & 0.3 & 0.3 & 1.0 \\
\hline 250-999 & $6-10$ & 0.1 & 0.0 & 0.5 & 0.6 & 1.2 \\
\hline 250-999 & $11+$ & 0.0 & 1.8 & 4.5 & 6.3 & 11.2 \\
\hline $1 \mathrm{k}-4999$ & $1-5$ & 0.1 & 0.0 & 0.0 & 0.1 & 0.6 \\
\hline $1 \mathrm{k}-4999$ & $6-10$ & 0.1 & 0.0 & 0.4 & 0.4 & 0.9 \\
\hline $1 \mathrm{k}-4999$ & $11+$ & 0.2 & 0.0 & 5.9 & 6.2 & 13.6 \\
\hline 5k-9999 & $1-5$ & 0.0 & 0.0 & 0.0 & 0.0 & 0.3 \\
\hline 5k-9999 & $6-10$ & 0.1 & 0.0 & 0.0 & 0.1 & 0.2 \\
\hline 5k-9999 & $11+$ & 0.1 & 0.0 & 2.5 & 2.6 & 5.3 \\
\hline $10 \mathrm{k}+$ & $6-10$ & 0.2 & 0.0 & 0.1 & 0.2 & 0.3 \\
\hline $10 \mathrm{k}+$ & $11+$ & 0.5 & 0.1 & 6.3 & 6.9 & 19.6 \\
\hline
\end{tabular}

Source: Census LBD. CD = Creative Destruction, NV = New Varieties, and OI = Own Innovation (incumbents improving on their own varieties). Firm size is the sum of employment across all of its plants. Firm age is the difference between the year of observation minus the birth year of the firm's first plant. 


\section{References}

Acemoglu, Daron, “Labor- and Capital-Augmenting Technical Change," Journal of the European Economic Association, 2003, 1 (1), 1-37.

_ , Introduction to Modern Economic Growth, Princeton University Press, 2011.

Aghion, Philippe and Peter Howitt, “A Model of Growth Through Creative Destruction,” Econometrica, 1992, 60 (2), 323-351.

_ and _, The Economics of Growth, Massachusetts Institute of Technology (MIT) Press, 2009.

_ , Antonin Bergeaud, Timo Boppart, Peter J. Klenow, and Huiyu Li, "Missing Growth from Creative Destruction,” American Economic Review, 2019, 109 (8), 2795-2822.

$\ldots, \ldots, \ldots, \ldots$, and _ , "A Theory of Falling Growth and Rising Rents,” NBER Working Paper 26448, 2020.

_ , Nick Bloom, Richard Blundell, Rachel Griffith, and Peter Howitt, "Competition and Innovation: An Inverted-U Relationship," Quarterly Journal of Economics, 2005, 120 (2), 701-728.

_ , Ufuk Akcigit, and Peter Howitt, "What Do We Learn from Schumpeterian Growth Theory?," Handbook of Economic Growth, 2014, 2, 515-563.

Akcigit, Ufuk and Sina T. Ates, “What Happened to U.S. Business Dynamism?,” NBER Working Paper 25756, 2019.

— and William R. Kerr, "Growth through Heterogeneous Innovations," Journal of Political Economy, 2018, 126 (4), 1374-1443.

Atkeson, Andrew and Ariel Burstein, "Aggregate Implications of Innovation Policy," Journal of Political Economy, 2019, 127 (6), 2625-2683.

Baily, Martin Neil, Charles Hulten, and David Campbell, "Productivity Dynamics in Manufacturing Plants,” Brookings Papers: Microeconomics, 1992, 4, 187-267. 
Baqaee, David Rezza and Emmanuel Farhi, "Productivity and Misallocation in General Equilibrium,” Quarterly Journal of Economics, 2020, 135 (1), 105-163.

Bernard, Andrew B., Stephen J. Redding, and Peter K. Schott, "Multi-Product Firms and Product Switching," American Economic Review, 2010, 100 (1), 70-97.

Bloom, Nicholas, Charles I. Jones, John Van Reenen, and Michael Webb, “Are ideas getting harder to find?," NBER Working Paper 23782, 2017.

Broda, Christian and David E Weinstein, "Globalization and the Gains from Variety," Quarterly Journal of Economics, 2006, 121 (2), 541-585.

Decker, Ryan A., John Haltiwanger, Ron S. Jarmin, and Javier Miranda, "Declining Dynamism, Allocative Efficiency, and the Productivity Slowdown," American Economic Review, 2017, 107 (5), 322-26.

Decker, Ryan, John Haltiwanger, Ron Jarmin, and Javier Miranda, “The Role of Entrepreneurship in U.S. Job Creation and Economic Dynamism," Journal of Economic Perspectives, 2014, 28 (3), 3-24.

Engbom, Niklas, "Firm and Worker Dynamics in an Aging Labor Market," unpublished paper, 2017.

Eslava, Marcela and John Haltiwanger, "The Life-Cycle Growth of Plants: The Role of Productivity, Demand and Distortions," unpublished paper, 2019.

Feenstra, Robert C., "New Product Varieties and the Measurement of International Prices," American Economic Review, 1994, 84 (1), 157-177.

Fernald, John G, "Productivity and Potential Output Before, During, and After the Great Recession," NBER Macroeconomics Annual, 2015, 29, 1-51.

Foster, Lucia, John C. Haltiwanger, and C.J. Krizan, "Aggregate Productivity Growth: Lessons from Microeconomic Evidence," New Developments in Productivity Analysis, 2001, 8, 303-372. 
_ , John Haltiwanger, and Chad Syverson, "Reallocation, Firm Turnover, and Efficiency: Selection on Productivity or Profitability?," American Economic Review, 2008, 98 (1), 394-425.

Garcia-Macia, Daniel, Chang-Tai Hsieh, and Peter J. Klenow, “How Destructive is Innovation?," Econometrica, 2019, 87 (5), 1507-1541.

Griliches, Zvi and Haim Regev, "Firm Productivity in Israeli Industry 1979-1988," Journal of Econometrics, 1995, 65 (1), 175-203.

Gutiérrez, Germán and Thomas Philippon, "Fading Stars," AEA Papers and Proceedings, 2019, 109, 312-316.

Haltiwanger, John, Ron S. Jarmin, and Javier Miranda, "Who Creates Jobs? Small versus Large versus Young," Review of Economics and Statistics, 2013, 95 (2), 347-361.

Hopenhayn, Hugo A., "Entry, Exit, and Firm Dynamics in Long Run Equilibrium," Econometrica, 1992, 60 (5), 1127-1150.

Hopenhayn, Hugo, Julian Neira, and Rish Singhania, "From Population Growth to Firm Demographics: Implications for Concentration, Entrepreneurship and the Labor Share," NBER Working Paper 25382, 2018.

Hottman, Colin J., Stephen J. Redding, and David E. Weinstein, "Quantifying the Sources of Firm Heterogeneity," Quarterly Journal of Economics, 2016, 131 (3), 12911364 .

Hsieh, Chang-Tai and Peter J. Klenow, "Misallocation and Manufacturing TFP in China and India," Quarterly Journal of Economics, 2009, 124 (4), 1403-1448.

_ and _ , "The Life Cycle of Plants in India and Mexico," Quarterly Journal of Economics, 2014, 129 (3), 1035-1084.

_ and _ , "The Reallocation Myth," Fostering a Dynamic Global Economy, 2017.

_ , _ , and Ishan B. Nath, "A Global View of Creative Destruction," NBER Working Paper 26461, 2019. 
Jones, Charles I., "R\&D-Based Models of Economic Growth,” Journal of Political Economy, 1995, 103 (4), 759-784.

_ , “Life and Growth,” Journal of Political Economy, 2016, 124 (2), 539-578.

Klette, Tor Jakob and Samuel Kortum, "Innovating Firms and Aggregate Innovation,” Journal of Political Economy, 2004, 112 (5), 986-1018.

Krusell, Per, "How is R\&D Distributed Across Firms? A Theoretical Analysis," unpublished paper, 1998.

Lentz, Rasmus and Dale T. Mortensen, "An Empirical Model of Growth through Product Innovation," Econometrica, 2008, 76 (6), 1317-1373.

Liu, Ernest, Atif Mian, and Amir Sufi, "Low Interest Rates, Market Power, and Productivity Growth," NBER Working Paper 25505, 2019.

Lucas, Robert E. Jr. and Benjamin Moll, "Knowledge Growth and the Allocation of Time," Journal of Political Economy, 2014, 122 (1), 1-51.

Luttmer, Erzo G.J., “On the Mechanics of Firm Growth,” Review of Economic Studies, 2011, 78 (3), 1042-1068.

Mankiw, N. Gregory, David Romer, and David N. Weil, "A Contribution to the Empirics of Economic Growth," Quarterly Journal of Economics, 1992, 107 (2), 407-437.

Melitz, Marc J. and Sašo Polanec, "Dynamic Olley-Pakes Productivity Decomposition with Entry and Exit,” The RAND Journal of Economics, 2015, 46 (2), 362-375.

Olley, G. Steven and Ariel Pakes, "The Dynamics of Productivity in the Telecommunications Equipment Industry,” Econometrica, 1996, 64 (6), 1263-1297.

Peters, Michael, "Heterogeneous Mark-Ups, Growth and Endogenous Misallocation,” forthcoming in Econometrica, 2019.

_ and Conor Walsh, "Declining Dynamism, Increasing Markups and Missing Growth: The Role of the Labor Force," unpublished paper, 2019. 
Rivera-Batiz, Luis A. and Paul M. Romer, "Economic Integration and Endogenous Growth,” Quarterly Journal of Economics, 1991, 106 (2), 531-555.

Romer, Paul M., “Endogenous Technological Change,” Journal of Political Economy, 1990, 98 (5, Part 2), S71-S102.

Solow, Robert M., “A Contribution to the Theory of Economic Growth,” Quarterly Journal of Economics, 1956, 70 (1), 65-94. 